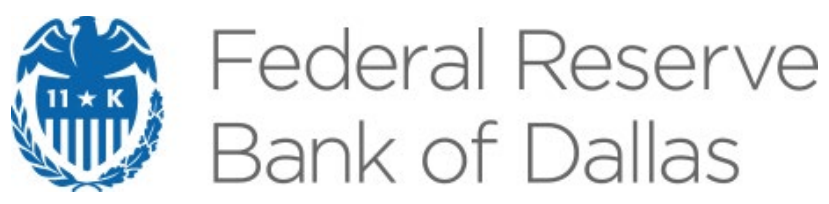

\title{
The Growth Effects of El Niño and La Niña: Local Weather Conditions Matter
}

Cécile Couharde, Olivier Damette, Rémi Generoso and Kamiar Mohaddes

\section{Globalization Institute Working Paper 374}

Research Department

https://doi.org/10.24149/gwp374

Working papers from the Federal Reserve Bank of Dallas are preliminary drafts circulated for professional comment. The views in this paper are those of the authors and do not necessarily reflect the views of the Federal Reserve Bank of Dallas or the Federal Reserve System. Any errors or omissions are the responsibility of the authors. 


\title{
The Growth Effects of EI Niño and La Niña: Local Weather Conditions Matter
}

\author{
Cécile Couharde ${ }^{\dagger}$, Olivier Damette ${ }^{\ddagger}$, Rémi Generoso $^{\S}$ and Kamiar Mohaddes ${ }^{ \pm}$
}

November 10, 2019

\begin{abstract}
This paper contributes to the climate-economy literature by analysing the role of weather patterns in influencing the transmission of global climate cycles to economic growth. More specifically, we focus on El Niño Southern Oscillation (ENSO) events and their interactions with local weather conditions, taking into account the heterogeneous and cumulative effects of weather patterns on economic growth and the asymmetry and nonlinearity in the global influence of ENSO on economic activity. Using data on 75 countries over the period 1975-2014, we provide evidence for the negative growth effects of ENSO events and show that there are substantial differences between its warm (EI Niño) and cold (La Niña) phases and between climate zones. These differences are due to the heterogeneity in weather responses to ENSO events, known as teleconnections, which has so far not been taken into account by economists, and which will become more important in the climateeconomy relationship given that climate change may substantially strengthen longdistance relationships between weather patterns around the world. We also show that the negative growth effects associated with these teleconnections are robust to the definition of ENSO events and more important over shorter meteorological onsets.
\end{abstract}

JEL Classification: C33, O40, Q54.

Keywords: Economic growth, ENSO events, weather shocks, climate change.

\footnotetext{
*We are grateful to Stefano Battiston, Lotanna Emediegwu, David Hendry, Robert Kaufmann, Claudio Morana, as well as participants of the 2018 Sustainability and Development Conference (University of Michigan), GDRIIDE Symposium (Clermont-Ferrand, France), CREATE (Laval University, Canada), 2019 AFSE Annual Meeting (Orléans, France), 2019 EMCC-IV Econometric Models of Climate Change Conference (Milan, Italy) for constructive comments and suggestions. The views in this paper are those of the authors and do not necessarily reflect the views of the Federal Reserve Bank of Dallas or the Federal Reserve System.

${ }^{\dagger}$ Cécile Couharde, EconomiX-CNRS, Université Paris Nanterre.

${ }^{\ddagger}$ Olivier Damette, BETA-CNRS, Université de Lorraine and Climate Economic Chair Paris associate.

$\S$ Corresponding author: Rémi Generoso, LEM-CNRS, Université de Lille, remi.generoso@univ-lille.fr.

${ }^{ \pm}$Kamiar Mohaddes, Judge Business School, University of Cambridge.
} 


\section{Introduction}

The climate-economy literature has mainly focused on cross-country analysis in order to quantify the effects of climate change and weather shocks on economic performance, such as agricultural output (Deschênes and Greenstone, 2007), conflict (Hsiang et al., 2011), labour productivity and economic growth (Burke et al., 2015; Kahn et al., 2019). ${ }^{1}$ While these cross-country studies are informative, they also have drawbacks as they tend to average temperature and precipitation data at the country level (leading to a loss of information, especially in geographically diverse countries), and more importantly they do not take into account the effects of climate/weather events on local weather conditions. Modelling the latter is important given that climate scientists argue that climate change may substantially strengthen long-distance relationships between weather patterns around the world, commonly referred to as teleconnections (Power and Delage, 2018; IPCC, 2019). We contribute to the economic literature by analysing the role of weather patterns in influencing the transmission of global climate cycles to economic growth. More specifically, we focus on El Niño Southern Oscillation (ENSO) events and their interactions with local weather conditions, taking into account the heterogeneous and cumulative effects of weather patterns on economic growth and the asymmetry and nonlinearity in the global influence of ENSO on economic activity.

Among teleconnections, ENSO is the most important coupled ocean-atmosphere phenomena that alters the weather conditions of distant parts of the globe. Its warm phase (El Niño) is associated with a band of warm ocean water that develops in the central and east-central equatorial Pacific while its cold phase (La Niña) is characterized by below-average Sea Surface Temperatures (SST) in the eastern Pacific. The ENSO cycle, including both El Niño and La Niña, causes global changes in temperature and rainfall on average every two to seven years which, in turn, substantially influence economic activity. Given that global warming could play an important role in the rise of teleconnections' strength and of extreme weather events related to ENSO (Cai et al., 2015; Fasullo et al., 2018; IPCC, 2019), ${ }^{2}$ providing a well-identified understanding of channels through which ENSO affects economic performance may be essential for assessing the potential economic implications of climate change.

Although ENSO events have been observed throughout time and identified by historians as exacerbating economic and social disasters (Parker, 2013), they have only recently been taken into account by economists. As a consequence, the literature focusing on the economic impacts of ENSO is still developing. Some studies

\footnotetext{
${ }^{1}$ See also the recent surveys by Tol (2009) and Dell et al. (2014). Hsiang and Kopp (2018) have put forward the central role that economists might play in the quest for tackling the effects of global warming and helping climate science advance.

${ }^{2}$ The relationship between changes in global temperatures and ENSO has also been highlighted by Parker (2013). In his book, he documents that during the little ice age period (around 1550-1700), twice as many El Niño episodes were observed. Moreover, he stresses the potential causal role of this period of prolonged cold in the higher occurrence of wars, civil wars and rebellions compared to any previous or subsequent age.
} 
examine whether ENSO influences economies around the world, ${ }^{3}$ with the evidence generally suggesting that it does. Estimating several vector autoregressive (VAR) models, Brunner (2002) found evidence of ENSO effects on growth and inflation in the G7 countries. Since this seminal paper, only two studies have explored the relationship between ENSO and economic performances from a multi-country perspective (Cashin et al., 2017; Smith and Ubilava, 2017). Cashin et al. (2017) estimate a Global VAR model covering 21 countries/regions over the period 1979Q2 to 2013Q1 and show that El Niño events have a direct effect on economic activity for those countries that are at the epicenter of an El Niño event (Australia, Chile, Indonesia, New Zealand, and Peru). The study also highlights important indirect effects on economic growth, inflation and commodity prices through trade and financial channels for countries that are geographically more distant from the phenomenon. Smith and Ubilava (2017) analyze the effect of this atmospheric phenomenon in 69 developing countries on growth rate and agricultural value-added using both linear and threshold panel regressions. They show that El Niño events have negative impacts on economic growth while the effects of La Niña events are much less significant. Their results also indicate that important regional heterogeneities exist when it comes to ENSO shocks, with stronger evidence of El Niño growth effects in tropical countries.

While these studies have provided an understanding of channels through which ENSO can directly influence economic growth, including real prices of primary commodities (Brunner, 2002), trade (Cashin et al., 2017), or agriculture share in total output (Smith and Ubilava, 2017), insights concerning the role of weather patterns that are potentially correlated with ENSO events have not yet been integrated into econometric studies. The climate literature has, however, shown that ENSO events have large scale and regional impacts on weather patterns and seasonal climate averages (Poveda and Mesa, 1997; Vicente-Serrano et al., 2011). Based on these findings, weather variables should be considered in the climate-growth nexus, for at least three reasons. First, ENSO influences climate variability at a global scale with large differences in spatial patterns while countries' weather conditions have important effects on economic performances (Dell et al., 2014). It is then likely that the most vulnerable countries to climate hazards will also be more affected by an ENSO event. Second, ENSO signals may have localized impacts that cannot be reflected in economic growth without explicitly taking into account their impacts on countries' weather conditions. A third issue is that each ENSO event is different and occurs in conjunction with other climatic events (Davey et al., 2014). The corollary is that distinct ENSO episodes recording identical SST anomalies may be different in intensity at the regional or country level. Such temporal asymmetries may then mask other important macroeconomic implications of ENSO shocks (Smith and Ubilava, 2017).

\footnotetext{
${ }^{3}$ Most research has been conducted using data from a single country. See for example Berry and Okulicz-Kozaryn (2008) who analyze the relationships between ENSO, U.S. inflation and economic growth over a long time span and studies focusing on ENSO effects on domestic agricultural sector (Dilley, 1997; Naylor et al., 2001).
} 
In the light of this, in this paper we assess the impacts of ENSO on economic growth by distinguishing its global effects from its specific effects channeled through countries' hydro-meteorological conditions. The inclusion of weather variables in panel estimation makes it possible to control for time-varying and country-specific effects of ENSO, therefore illustrating its heterogeneous and delayed impact on GDP growth, as discussed in the climate literature (Vicente-Serrano et al., 2011; Kumar and Hoerling, 2003; Poveda and Mesa, 1997). Moreover, given that ENSO shocks are only slowly absorbed by the economy, we supplement our analysis by considering their role in affecting total factor productivity. We use the usual ENSO regime categorization that defines El Niño (La Niña) regimes by positive (negative) values of SST anomalies together with a finer classification according to the duration and the magnitude of SST anomalies. To assess weather conditions, we use the Standardized Precipitation and Evapotranspiration Index (SPEI) developed by Vicente-Serrano et al. (2010). This indicator incorporates both precipitation and temperature data of current weather conditions, plus their cumulative patterns of previous months. This multi-scalar feature captures medium to long-run effects of changes in weather patterns, as discussed by Dell et al. (2014), ${ }^{4}$ and therefore allows us to identify the persistent economic impacts of ENSO through the present and past weather conditions in each country. As the weather response to ENSO events typically depends on climatic conditions, our empirical model allows for a differential effect of ENSO shocks according to the type of climate regime that prevails in each country of our sample.

Using data on 75 countries over the 1975-2014 period, we show that ENSO events have heterogeneous impacts on economic activity depending on the type of climate. We also highlight that the observed disparities are explained by the heteregeonous and persistent impacts of ENSO on weather patterns across countries. In particular, El Niño phases have a persistent negative effect through drier conditions in already dry areas located in the tropical sphere. In contrast, wet parts of the arid/temperate zone are negatively affected by La Niña events, the year following their occurrence, through increased pluvial periods. These findings are highly robust to the use of an alternative categorization of ENSO regimes and of weather conditions at different time-scales as well as across estimation methodologies.

The rest of the paper is organized as follows. To set the stage, Section 2 begins by describing the data set and presenting some stylized facts. Section 3 lays out the empirical methodology and benchmark results. In Section 4 we provide evidence for the robustness of our results when accounting for ENSO extreme events and the possible influence of the duration of weather patterns. Finally, Section 5 offers some concluding remarks.

\footnotetext{
${ }^{4}$ Dell et al. (2014) stress that the intensification issue remains a challenge and could be addressed by using a statistical approach where weather variables are interacted with their own lags or by using more advanced climate indices that reflect cumulative effects of weather shocks.
} 


\section{Data and stylized facts}

Our sample consists of 75 countries listed in Table A.1 of the Appendix and is an unbalanced panel with data spanning from 1975 to $2014 .{ }^{5}$ The sample includes low-income, lower-middle-income and upper-middleincome economies as classified by the World Bank.

\subsection{ENSO phases and weather conditions}

One of our main variables of interest, the measure of ENSO events, is taken from the National Oceanic and Atmospheric Administration (NOAA) of the United States dataset, which provides monthly data on the Oceanic Niño Index (ONI) from 1950 to 2018. ${ }^{6}$ The underlying methodology used to derive these series consists of three steps. The average SST is calculated for each month in the Niño 3.4 region, spanning from $170^{\circ} \mathrm{W}-120^{\circ} \mathrm{W}$ longitude and $5^{\circ} \mathrm{N}-5^{\circ} \mathrm{S}$ latitude, and then averaged with values from the previous and following months. This running 3-month average is compared to a 30-year average of the three most recent complete decades, updated in each new decade. The observed difference from the average SST in that region corresponds to the ONI value for that 3-month season (i.e., the 3-month mean SST anomaly). Following Hsiang et al. (2011) and Sarachik and Cane (2010), ENSO phases are identified by averaging ONI values between the month of May of a given year and the month of February of the following year, i.e. the period over which the El Niño and La Niña events are typically most active. Positive (negative) values of the ONI reflect warming (cooling) SSTs prevailing during El Niño (La Niña) phases (Figure 1). ${ }^{7}$

Although annualized series reflecting SST anomalies are the most straightforward measures of ENSO, they may fail to identify the different types and intensities of El Niño and La Niña events. Recent studies have shown that the duration of and the intensity with which ENSO events propagate throughout the globe are crucial to identify their teleconnection patterns. ${ }^{8}$ In particular, depending on their duration and their intensities, El Niño and La Niña events may be moderate or strong and thus significantly different from the neutral regime in which weak events prevail. Therefore, the real impacts of ENSO may not be adequately detected through SST anomalies captured by positive and negative values of the ONI variable.

\footnotetext{
${ }^{5}$ The year 1975 is used as the starting date since the ENSO properties and dynamics have changed over time (Aiken et al., 2013), with lower frequency and stronger amplitude since the late 1970s (An and Wang, 2000).

${ }^{6}$ We use this index because it corresponds to the operational definition used by the NOAA. Moreover, this index has a strong correlation with both the Niño 3.4 index and the surface atmospheric pressure-based Southern Oscillation Index (SOI) (Bamston et al., 1997), which also explains its widespread use in the literature. See Table A.2 of the Appendix.

${ }^{7}$ ONI series are taken from the R "rsoi" package : https://github.com/boshek/rsoi

${ }^{8}$ See Trenberth (1997) for a detailed discussion of the different definitions of ENSO.
} 
Figure 1: Evolution of the Oceanic Niño Index since $1975\left({ }^{\circ} \mathrm{C}\right)$

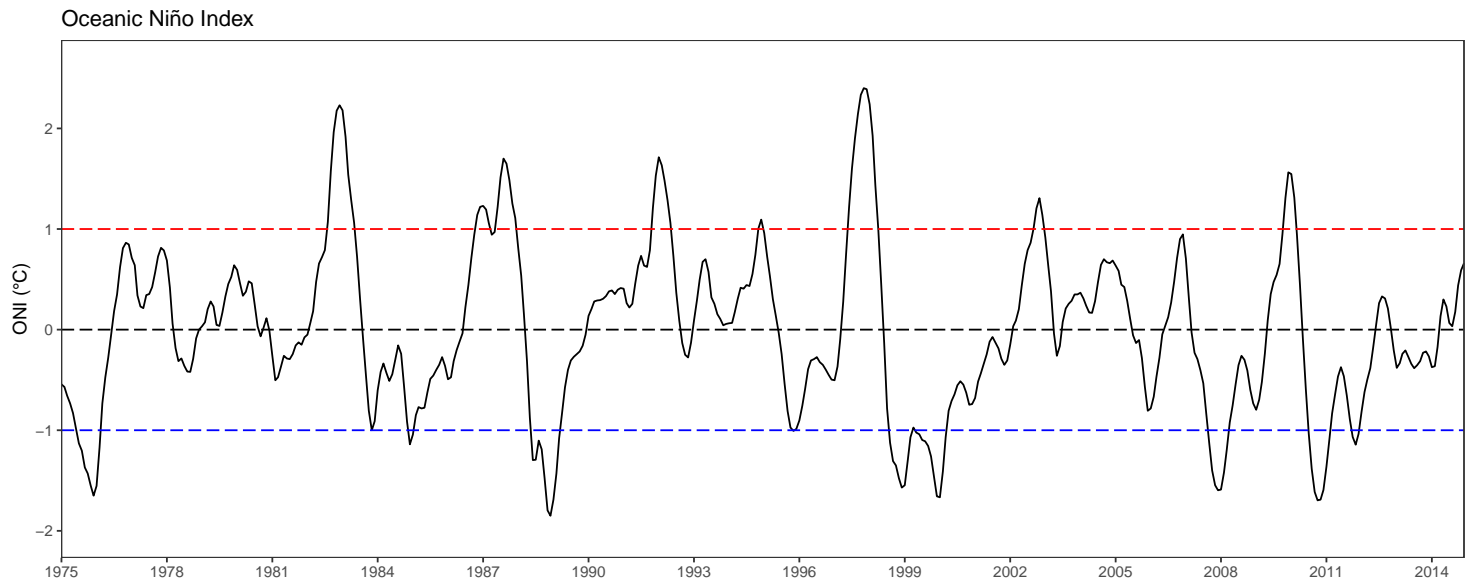

Note: The red (blue) line indicates the threshold $S S T$ of $+1^{\circ} \mathrm{C}\left(-1^{\circ} \mathrm{C}\right)$ that categorizes the ENSO phase as El Niño (La Niña). Source: monthly data from NOAA.

To deal with this issue, and for the sake of robustness, we define a categorical variable reflecting each state of ENSO following the standard decision process in determining moderate to strong ENSO events as proposed by the Climate Prediction Center. ${ }^{9}$ El Niño episodes are defined by an Oceanic Niño Index $1^{\circ} \mathrm{C}$ warmer than normal for at least five consecutive overlapping 3-month seasons. La Niña episodes arise when the Oceanic Niño Index is $1^{\circ} \mathrm{C}$ cooler than normal for at least five consecutive overlapping 3-month seasons (Figure 1). Beyond these thresholds, ENSO events are seen as moderate or strong. ENSO episodes that do not fall in these two categories correspond to weak events and are thus considered as neutral. El Niño and La Niña episodes categorized as weak, moderate, or strong in our sample period (1975-2014) are reported in Table 1.

Table 1: Years characterized by weak, moderate, and strong ENSO events

\begin{tabular}{cccccc}
\hline \multicolumn{3}{c}{ El Niño } & \multicolumn{3}{c}{ La Niña } \\
\hline Weak & Moderate & Strong & Weak & Moderate & Strong \\
\hline 1977 & $1994^{a}$ & 1987 & 1983 & $1995^{a}$ & 1975 \\
$1979-80$ & $2002^{a}-2003^{a}$ & 1991 & 1984 & & 1988 \\
$2004-05$ & 2009 & 1992 & $2000-01$ & & $1998-1999$ \\
$2006-07$ & & 1997 & $2005-06$ & & 2007 \\
2014 & & & $2008-09$ & & $2010-2011$ \\
\hline
\end{tabular}

Note: ${ }^{a}$ Years characterized by events of lower amplitude but reported by NOAA as having significant repercussions.

The other variable of interest, a measure of weather conditions, is taken from the Global SPEI database ${ }^{10}$

\footnotetext{
${ }^{9}$ The Climate Prediction Center is a branch of the National Weather Service of the United States.

${ }^{10}$ We use version 2.5 of the Global SPEI database : http://spei.csic.es/database.html
} 
which provides monthly values of the Standardized Precipitation-Evapotranspiration Index (SPEI) at the global scale, with a 0.5 degrees spatial resolution and for the period between January 1901 and December 2014. The main advantage of this index is that it captures the impact of both precipitation and temperature variability and extremes on water demand. The SPEI is, therefore, particularly suited for detecting dry and wet conditions in the context of global warming (Beguería et al., 2014). It is also relevant for the analysis and the assessment of time-varying economic risks at a large geographical scale since its standardization makes it comparable in time and space. Positive (negative) SPEI indicates wetter (drier) hydro-climatic conditions. ${ }^{11}$ Another advantage of the SPEI is that it can be calculated at various time scales (between 1 and 48 months) over which water deficits/surplus accumulate reflecting the different response times of hydrological and agricultural systems to weather conditions. This multi-scalar feature allows us to take into account the structural effects of ENSO that depend on the crops' response, natural vegetation, and hydrological systems. Furthermore, using time scales representing short to medium term dry or wet spells helps us to identify the lags that commonly occur in the response of climatic conditions to ENSO events. Indeed, El Niño and La Niña phases exert differing impacts depending on the hydrological cycle (Penalba and Rivera, 2016), and in turn, their economic impact can be exacerbated by the climatic conditions prevailing in previous months. The SPEI constitutes, therefore, an efficient way to address the intensification process of climate effects by taking into account the time structure of weather shocks in the economic response to ENSO events. We use as a benchmark indicator the 6-month SPEI, given its ability to capture seasonal to medium-term trends in weather conditions that mainly affect agricultural systems; but also show the robustness of our results using the 3-month and 12-month SPEI.

A key challenge of using weather indicators is to aggregate gridded SPEI observations in order to obtain indexes consistent with economic data and reflecting adequately the climate variability experienced by each country. The procedure of averaging gridded weather data at the country level leads to loss of relevant information for two main reasons. First, changes in temperature, precipitation, and other climate parameters usually vary within countries, with differential exposure and uneven consequences at the local level. Ignoring this scale-dependency issue can be problematic as extreme conditions at the local level are likely to be obscured by using averaged data at the country level, and lead to a biased assessment of weather conditions. Secondly, this approach could fail to identify climate shocks affecting human activities especially if large areas where little economic activity and sparse populations dominate, such as deserts or rain forests (Dell et al., 2014). To deal with this problem and to derive consistent country-level series, we assign individual gridded SPEI values

\footnotetext{
${ }^{11}$ Different intensities in hydro-climatic conditions can be identified, according to threshold values reached by the SPEI, as detailed in Table B.1 of the Appendix.
} 
over cropland areas to individual countries to arrive at country-wide time series. As the main channel linking ENSO shocks and economic growth operates through shocks to agricultural incomes, restricting weather conditions to cropland areas allows us to isolate the component of climate variability, which is relevant for agriculture. Another advantage of this aggregation approach is that it provides a consistent measure of climate variability within a country as cropland areas broadly share the same weather conditions. To retrieve the climate variability in cropland areas, we rely on the Global Land Cover SHARE (GLC-SHARE) prepared by FAO's Land and Water Division (NRL). This database provides information on mainland use and land cover shares, on each 1 by 1-kilometer plot of land covering the entire globe. We construct monthly SPEI values at the country level by overlaying grid cells of SPEI over cropland distribution in each country and averaging the SPEI values over each country's arable and permanent croplands. See section B.2 of the Appendix for an extensive discussion on how the average SPEI for each country is constructed.

\subsection{Identifying climate groups}

To capture the variability of ENSO impacts across countries, with some regions considered more "teleconnected" to ENSO (continental tropics) than others (mid-latitudes regions), we partition the globe into two groups - tropical/humid and temperate/arid countries - based on how coupled their climates are to ENSO, according to the Köppen-Geiger Climate Classification (Kottek et al., 2006). However, in order to have country groups consistent with SPEI values calculated at the country level, we identify climatic conditions which only prevail in cropland areas within each country. Specifically, we define tropical/humid countries as those with $50 \%$ or more of their total cropland areas falling into the four subtypes of tropical climates. ${ }^{12}$ Countries having a temperate/arid climate refer to those with $50 \%$ or more of their total cropland area characterized by one type of arid or mild temperate climates. ${ }^{13}$ The list of countries included in each of these two climate groups is provided in Table A.1 of the Appendix. ${ }^{14}$

The widespread influence of ENSO events on local weather patterns is shown in Figure 2 which reports SPEI anomalies, defined as the difference between the SPEI values prevailing during normal conditions and those prevailing during an ENSO episode (Figure 2a). To illustrate the persistent impact of El Niño and La Niña on weather patterns, we also report SPEI anomalies during the year following an ENSO episode (Figure $2 b)$.

Figure 2 shows that most countries have less precipitation during an El Niño episode. In Central America, El Niño is associated with serious drought in Mexico, Guatemala, Honduras, and El Salvador. Some

\footnotetext{
12 i.e. tropical rain forest, tropical monsoon, tropical savannah with dry summer, and tropical savannah with dry winter.

${ }^{13}$ Classes of arid climates refer to desert, steppe-hot arid and steppe-cold arid while subtypes of mild temperate climates include mild temperate with dry summer, mild temperate with dry winter, mild temperate fully humid warm summer, mild temperate fully humid cool summer.

${ }^{14}$ The classification is close to the one used in the literature except for large countries, such as India, and Mexico.
} 
Caribbean countries also suffer from drought. In addition, El Niño years lead to drought in Africa, as countries (such as Mali, Sudan, and Nigeria) tend to see lower SPEI during an El Niño event while droughts occur in the already very dry south of the continent (Mozambique, and Botswana). Moreover, other notable dry places include Indonesia, South and South-East Asia, and Australia. In general, La Niña effects on weather patterns are the opposite of those induced by El Niño resulting in wetter-than-normal conditions in Southern Africa and in the central Andes. Very heavy rain and flooding due to La Niña is also reported in the Philippines, Malaysia, Indonesia, and Australia. In contrast, many droughts are reported in Argentina, Chile and over East Africa following La Niña events. Finally, the surface extent and duration of the SPEI anomalies show that large areas of the world have SPEI anomalies lasting several months, confirming that the effects of El Niño and La Niña events on weather patterns can spread over many seasons (Vicente-Serrano et al., 2011; Kumar and Hoerling, 2003; Poveda and Mesa, 1997). One year after the occurrence of ENSO events, El Niño still affect most of Indonesia, the Indochina Peninsula, parts of Africa, and Australia whereas La Niña leads to substantially more precipitation as compared to neutral ENSO regimes in Africa and South East Asia.

Figure 2: Difference between the SPEI average during El Niño (La Niña) years and neutral years $(1975$ - 2014)

(a) Immediate effect

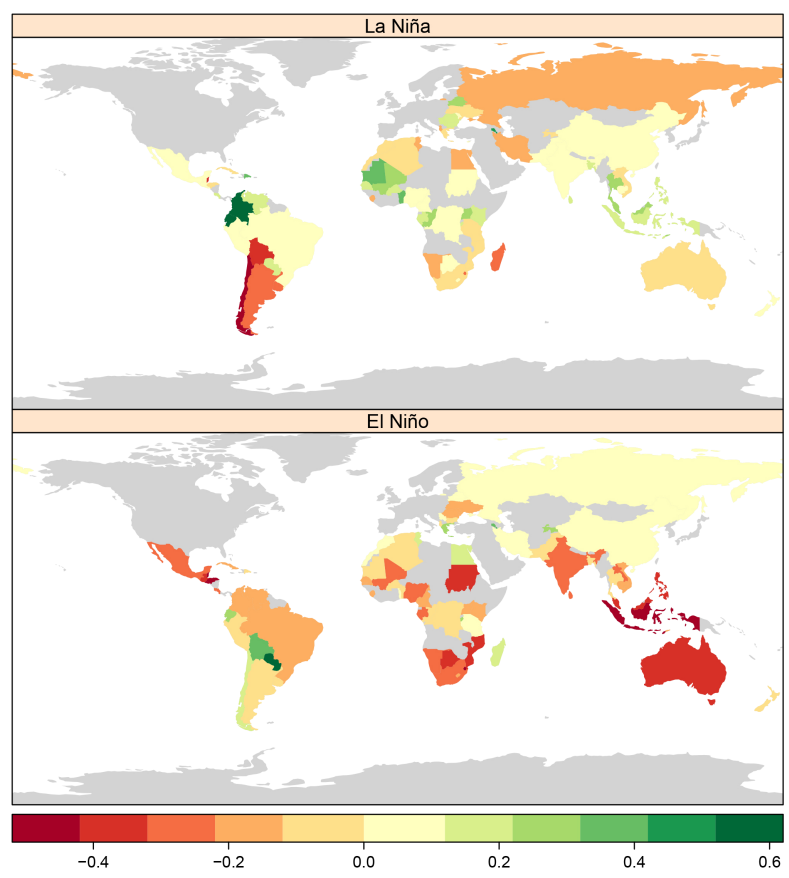

(b) Persistent effect

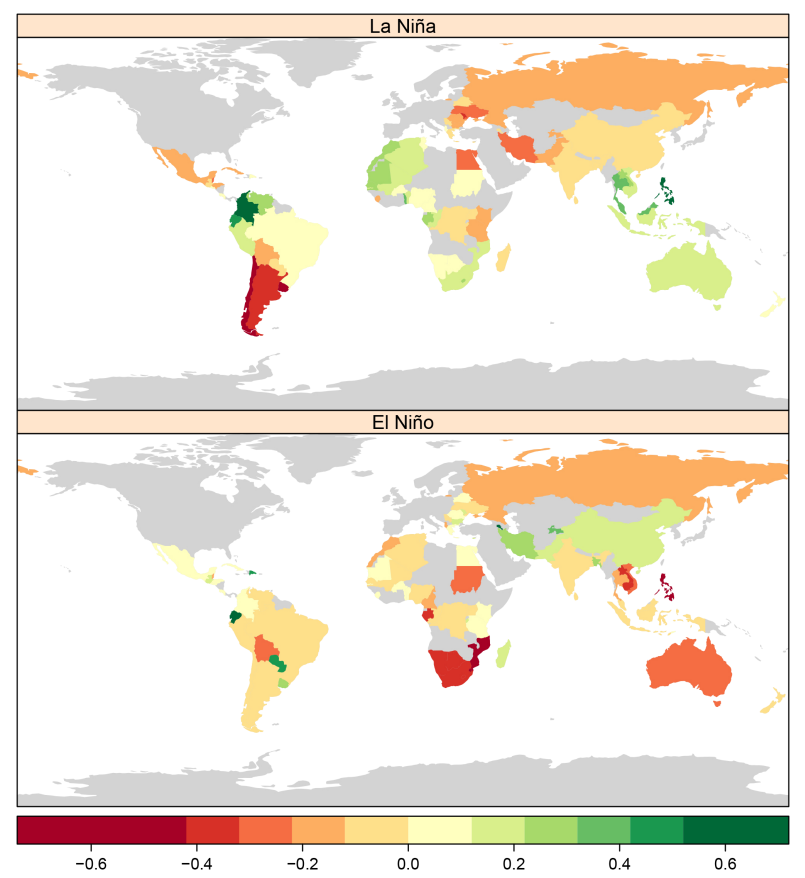

Note: Map (a) shows, for each country, the difference between the average of SPEI during the El Niño (La Niña) years and that during years characterized by a neutral ENSO regime. The persistent effect (map b) is calculated as the average difference between the SPEI the year following an El Niño (La Niña) shock and the years characterized by a neutral regime. Countries are color-coded on the basis of their SPEI anomalies: red (green) for countries with drier (wetter) conditions than those prevailing during normal conditions. Deeper is the color, higher are the SPEI anomalies. 


\subsection{Real income growth and ENSO events}

As the main purpose of this paper is to assess the growth effects of ENSO events, we obtain real GDP per capita from the recent version of the Penn World Table database. In Table 2, we report the means, standard deviations, and ranges for the 6-month SPEI and the real GDP per capita growth by climate areas (tropical/humid and temperate/arid). ${ }^{15}$

Table 2: Summary statistics by climate areas

\begin{tabular}{lccccccccc}
\hline \multirow{2}{*}{ Countries } & \multicolumn{4}{c}{ 6-month SPEI } & \multicolumn{4}{c}{ Growth rates } \\
\cline { 3 - 10 } & $\mathrm{n}$ & $\operatorname{mean}$ & $\min$ & $\max$ & $\mathrm{sd}$. & mean & $\min$ & $\max$ & $\mathrm{sd}$. \\
\hline All & 75 & -0.0292 & -1.772 & 2.348 & 0.5212 & 0.0167 & -0.5226 & 0.2833 & 0.0520 \\
Tropical \& humid & 39 & -0.0110 & -1.772 & 2.348 & 0.5197 & 0.0165 & -0.2983 & 0.2833 & 0.0165 \\
Temperate \& arid & 36 & -0.0516 & -1.559 & 1.958 & 0.5265 & 0.0168 & -0.5226 & 0.2571 & 0.0579 \\
\hline
\end{tabular}

According to the mean value of SPEI and real GDP per capita growth, few differences are apparent between the two climate areas. However, given the diverse geographic and economic conditions as well as climatic variability within these two areas, it is unlikely that the means are completely homogeneous across all countries and over time, as indicated by the high standard deviations. In order to investigate this further, Figure 3 displays the distribution of economic growth according to ENSO episodes for tropical/humid and temperate/arid countries.

As can be seen from Figure 3 the contemporaneous effects of El Niño phases suggest a lower average rate of growth as compared to the neutral and La Niña phases, in line with what has been reported in the literature. The delayed response of GDP growth to ENSO events remains, on the contrary, less clear. Indeed, no distinct differences can be observed across growth averages when considering lagged ENSO events. Importantly, there is a significant dispersion of real GDP growth across countries, illustrating the strong heterogeneity in countries' responses to ENSO events. This cross-country dispersion can be explained by many factors among which weather conditions play a key role due to their heterogeneous responses to ENSO events and their differentiated effects on countries' economic growth. The following section aims to investigate this issue.

\footnotetext{
${ }^{15}$ Table A.3 in the Appendix provides a detailed overview of the variables included in our dataset.
} 
Figure 3: Real GDP per capita growth and ENSO events

(a) Tropical \& humid countries
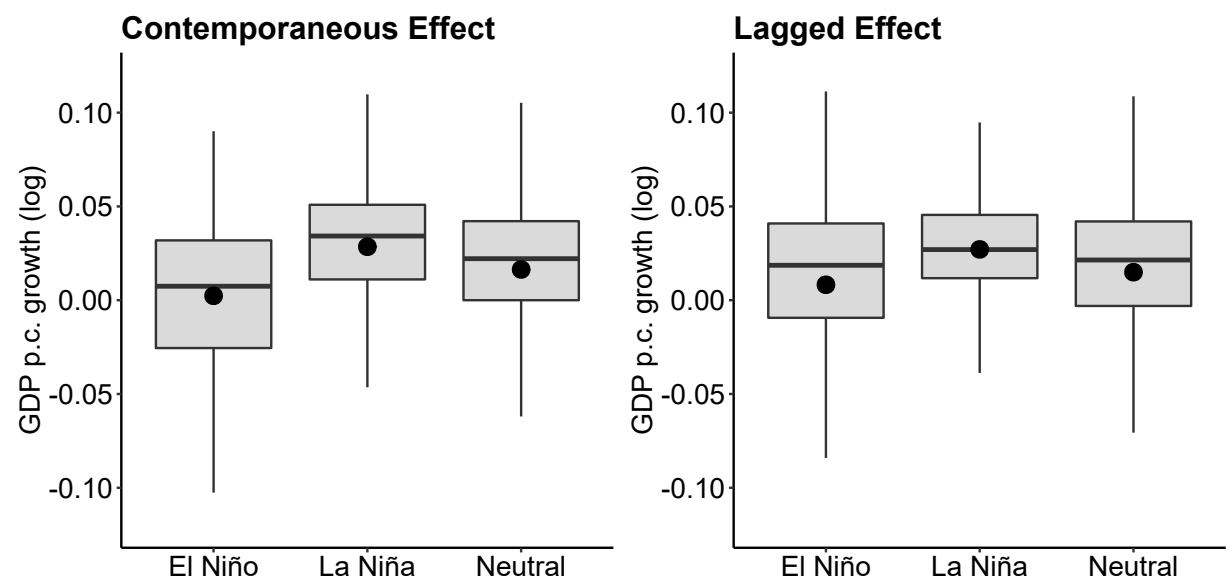

(b) Arid \& temperate countries
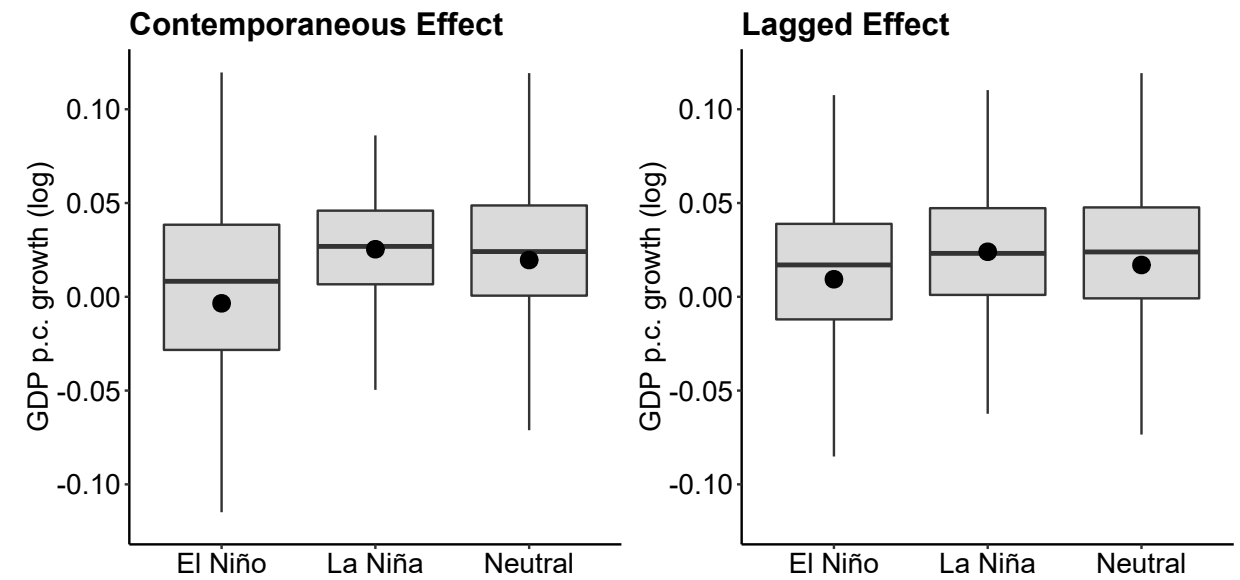

Note: The figure shows the distribution of the economic growth according to ENSO cycles for the current year (contemporaneous effect) and the year following any event (lagged effect).

\section{Empirical results}

\subsection{Econometric methodology}

Since ENSO impacts can extend beyond a calendar year and may also be temporally displaced, we estimate the contemporaneous as well as the lagged growth effects of ENSO events. To test our central hypothesis, we use interaction terms to assess how ENSO events influence growth under certain weather conditions. Our 
main specification is then given by: ${ }^{16}$

$$
\Delta y_{i, t}=\lambda+\alpha O N I_{t}+\beta S P E I_{i, t}+\gamma O N I_{t-1}+\delta\left(O N I_{t-1} \times S P E I_{i, t}\right)+\mu_{i}+\varepsilon_{i, t}
$$

where $y_{i, t}$ is the $\log$ of real GDP per capita of country $i$ in year $t, O N I_{t}$ is a vector of variables depicting the effects of ENSO events captured by annualized ONI values in year $t, S P E I_{i, t}$ is a vector of weather conditions measured by the 6-month SPEI, and the interaction term, $\left(O N I_{t-1} \times S P E I_{i, t}\right)$, permits us to assess whether ENSO events have a different influence on growth in countries where wet conditions prevail in cropland areas than in countries where these areas are rather characterised by dry conditions.

Equation (1) imposes a monotonic relationship between ENSO events and economic growth by assuming that climate anomalies related to La Niña events can be regarded as a mirror image of those associated with El Niño events. However, the climatology literature has produced considerable evidence on the asymmetry between El Niño and La Niña events (Burgers and Stephenson, 1999; Jin et al., 2003b; An and Jin, 2004; An et al., 2005; Zhang et al., 2015) mainly due to nonlinear responses in the atmosphere to the underlying SST anomalies (Hoerling et al., 1997; Jin et al., 2003a). To address this asymmetry issue, we follow Smith and Ubilava (2017) and interact the variable ONI with a Heaviside indicator that partitions the variable ONI into positive and negative values:

$$
\begin{aligned}
\Delta y_{i, t} & =\left[\alpha_{1} O N I_{t}+\beta_{1} S P E I_{i, t}+\gamma_{1} O N I_{t-1}+\delta_{1}\left(O N I_{t-1} \times S P E I_{i, t}\right)\right] I(.) \\
& +\left[\alpha_{2} O N I_{t}+\beta_{2} S P E I_{i, t}+\gamma_{2} O N I_{t-1}+\delta_{2}\left(O N I_{t-1} \times S P E I_{i, t}\right)\right](1-I(.)) \\
& +\lambda+\mu_{i}+\varepsilon_{i, t}
\end{aligned}
$$

where $I($.$) is the Heaviside function such that:$

$$
I(.)=\left\{\begin{array}{lll}
1 & \text { if } \quad O N I_{t} \geq 0 & (\text { El Niño }) \\
0 & \text { if } \quad O N I_{t}<0 & \text { (La Niña) }
\end{array}\right.
$$

The standard methods of estimating ENSO events with panel data rely usually on fixed-effects models. The major drawback of these models is that they not directly address the important question of the spatial and temporal correlation of climate and weather conditions across countries. As noted by Beck and Katz (1995), coefficient estimates from standard panel estimators can be severely biased if cross-section dependence is present. A preliminary analysis of the data using OLS reveals evidence of nonspherical errors because

\footnotetext{
${ }^{16}$ We restrict our set of explanatory variables to climate and weather variables in order to avoid an "over-controlling problem" (Dell et al., 2014).
} 
of contemporaneous correlation across the units alongside heteroskedasticity and serial correlation. ${ }^{17}$ This finding is not surprising given that economic activity may spill over into contiguous or economically related countries and climate events, such as ENSO, cross countries' borders (Auffhammer et al., 2013). Parks (1967) proposed to improve inference and estimation efficiency using a feasible generalized least squares (FGLS) estimator that has been popularized by Kmenta (1986). However, this estimator has been shown to exhibit poor finite sample properties, with overconfident standard errors rendering hypothesis testing useless (Beck and Katz, 1995). ${ }^{18}$ To address these problems, we use Prais-Winsten estimates with a sandwich-type estimator of the covariance matrix developed by Beck and Katz (1995). The so-called panel-corrected standard errors (PCSE) are robust to very general forms of cross-sectional dependence as well as autocorrelated errors of type AR(1). Results from PCSE estimates are also compared with Driscoll and Kraay (1998) covariance matrix estimator for fixed effects regression. Driscoll and Kraay's methodology is consistent independently of the cross-sectional dimension $N$ and is robust to higher-order serial correlation. ${ }^{19}$

\subsection{Growth effects of ENSO events}

Tables 3 and 4 present the results of the regression analyses for tropical/humid and arid/temperate countries respectively. Each table includes two sets of results from PCSE and DK estimations. We first estimate equation (2) without any weather variable or interaction term between ONI and SPEI, as shown in columns (1) and (4) of Tables 2 and 3. We find that increasing positive values of the ONI has a contemporaneous negative effect on growth in countries located in tropical/humid areas, indicating that the El Niño regime leads on average to lower growth rates in those countries. Its impact is, however, weakly significant in arid/temperate areas. This first finding is consistent with the literature (Cashin et al., 2017; Smith and Ubilava, 2017). In contrast, the growth response to La Niña events is not significant, regardless of the climate type, confirming the asymmetric nature of ENSO.

When adding the SPEI variable, we note that the effect of weather conditions is positive and significant only in arid/temperate countries, showing a high vulnerability of this climate zone to droughts. Moreover, controlling for countries' specific weather conditions does not modify the results obtained regarding the ENSO's contemporaneous effect on growth. Indeed, the negative growth effect of El Niño phases is still

\footnotetext{
${ }^{17}$ Results of this preliminary analysis are reported in Tables C.1 and C.2 of the Appendix. Results reported in Table C.2 show that, for all variables, there is strong evidence against the null hypothesis of no cross-section dependence in the model's variables.

${ }^{18}$ The Parks-Kmenta Feasible Generalized Least Squares estimator (FGLS) cannot be estimated when the time period $(T)$ is less than the number of cross-sectional units $(N)$ since the associated error variance-covariance matrix cannot be inverted. Even when $T \geq N$, Beck and Katz (1995) showed that the estimated standard errors using the Parks-Kmenta approach generate confidence intervals that are significantly too small, often underestimating variability by $50 \%$ or more.

${ }^{19} \mathrm{We}$ have also tested the unit root null hypothesis in our panel data setting using the Cross-sectionally Augmented IPS (CIPS) panel unit root test advanced by Pesaran (2007), which allows for cross-sectional dependence. As is clear from Appendix Table B.3, the null hypothesis of a unit root is rejected for the variable SPEI. The null hypothesis of a unit root is not rejected for the level of $y$, while rejected for its first difference.
} 
significant only for tropical/humid countries, while la Niña has no significant impact in both climate areas. The climate-literature provides insights into the mechanisms responsible for this asymmetric feature of ENSO.

First, there is evidence that the observed El Niño is larger than that of La Niña, especially since the climate shift around the year 1975 (An and Jin, 2004). Furthermore, the overall effect of La Niña events is usually the result of more localized tropical convection anomalies than those observed during El Niño phases (Mason and Goddard, 2001), which could also account for this differentiated impact. Another explanation, well documented by the climate literature, is due to the delays in hydrological responses to ENSO events (see, e.g., Kumar and Hoerling (2003)). Accordingly, the impact of La Niña events is likely to propagate throughout weather conditions only with some delays after their occurrence.

Table 3: Contemporaneous and lagged impacts of ENSO events Tropical \& humid countries

\begin{tabular}{|c|c|c|c|c|c|c|}
\hline & \multicolumn{3}{|c|}{ PCSE estimates } & \multicolumn{3}{|c|}{ DK estimates } \\
\hline & (1) & (2) & $(3)$ & (4) & (5) & (6) \\
\hline $\mathrm{ONI}_{t} \geq 0$ & $\begin{array}{c}-0.0132^{* *} \\
(0.0059)\end{array}$ & $\begin{array}{c}-0.0121^{* *} \\
(0.0059)\end{array}$ & $\begin{array}{c}-0.0159^{* * *} \\
(0.0061)\end{array}$ & $\begin{array}{c}-0.0222^{* *} \\
(0.0088)\end{array}$ & $\begin{array}{c}-0.0213^{* *} \\
(0.0091)\end{array}$ & $\begin{array}{c}-0.0228^{* * *} \\
(0.0080)\end{array}$ \\
\hline $\mathrm{ONI}_{t}<0$ & $\begin{array}{l}-0.0023 \\
(0.0061)\end{array}$ & $\begin{array}{l}-0.0027 \\
(0.0060)\end{array}$ & $\begin{array}{l}-0.0050 \\
(0.0059)\end{array}$ & $\begin{array}{c}-0.0072 \\
(0.0065)\end{array}$ & $\begin{array}{l}-0.0075 \\
(0.0064)\end{array}$ & $\begin{array}{l}-0.0080 \\
(0.0067)\end{array}$ \\
\hline $\mathrm{SPEI}_{t}$ & & $\begin{array}{c}0.0045^{* *} \\
(0.0022)\end{array}$ & $\begin{array}{l}-0.0030 \\
(0.0037)\end{array}$ & & $\begin{array}{c}0.0037 \\
(0.0033)\end{array}$ & $\begin{array}{l}-0.0040 \\
(0.0048)\end{array}$ \\
\hline $\mathrm{ONI}_{t-1} \geq 0$ & & & $\begin{array}{c}-0.0101^{*} \\
(0.0060)\end{array}$ & & & $\begin{array}{c}-0.0148^{*} \\
(0.0075)\end{array}$ \\
\hline $\mathrm{ONI}_{t-1}<0$ & & & $\begin{array}{l}-0.0058 \\
(0.0057)\end{array}$ & & & $\begin{array}{l}-0.0073 \\
(0.0083)\end{array}$ \\
\hline $\mathrm{ONI}_{t-1} \geq 0 \times S P E I_{t}$ & & & $\begin{array}{c}0.0194^{* * *} \\
(0.0070)\end{array}$ & & & $\begin{array}{c}0.0173^{* * *} \\
(0.0058)\end{array}$ \\
\hline $\mathrm{ONI}_{t-1}<0 \times S P E I_{t}$ & & & $\begin{array}{c}0.0090 \\
(0.0074)\end{array}$ & & & $\begin{array}{l}0.0126^{*} \\
(0.0066)\end{array}$ \\
\hline Constant & $\begin{array}{c}0.0163 \\
(0.0126)\end{array}$ & $\begin{array}{c}0.0154 \\
(0.0125)\end{array}$ & $\begin{array}{c}0.0209 \\
(0.0128)\end{array}$ & $\begin{array}{c}0.0233^{* * *} \\
(0.0043)\end{array}$ & $\begin{array}{c}0.0232^{* * *} \\
(0.0043)\end{array}$ & $\begin{array}{c}0.0291^{* * *} \\
(0.0065)\end{array}$ \\
\hline Countries $(N)$ & 39 & 39 & 39 & 39 & 39 & 39 \\
\hline Observations $(N \times T)$ & 1521 & 1521 & 1521 & 1521 & 1521 & 1521 \\
\hline$R^{2}[$ within $]$ & 0.0778 & 0.0798 & 0.0889 & {$[0.0200]$} & {$[0.0218]$} & {$[0.0330]$} \\
\hline $\operatorname{PSAR}(1)$ & Yes & Yes & Yes & No & No & No \\
\hline MA(3) & No & No & No & Yes & Yes & Yes \\
\hline
\end{tabular}

Note: Prais-Winsten (PSCE) estimates and fixed effects (within) regression models with Driscoll and Kraay (DK) standard errors. ONI $\geq 0$ and ONI $<0$ stand respectively for El Niño and La Niña conditions. Standard errors are in parentheses. ${ }^{* * *},{ }^{* *}$, and $^{*}$ indicate respectively $1 \%, 5 \%$, and $10 \%$ significance levels. PSAR(1) stands for panel specific AR(1)-type autocorrelation. MA(3) denotes autocorrelation of the moving average type with automatic lag length. 
As shown in columns (3) and (6), which report the results of our specification (2), the existence of such delayed effects is confirmed. ENSO negatively affects GDP growth in both climate areas through its differing impacts on weather conditions. As can be seen, in tropical/humid areas, while the contemporaneous negative effect of ENSO remains unchanged, the coefficient on the interaction term between the positive lagged value of ONI and the SPEI is significant. This lagged impact through weather conditions can be explained by the role played by El Niño events on the occurrence of tropical droughts. Unlike other natural hazards, droughts tend to develop very slowly over time and preferentially during El Niño events in this part of the world with a linear relationship to the strength of El Niño (Vicente-Serrano et al., 2011; Lyon, 2004; Mason and Goddard, 2001). The delayed effect of El Niño events on economic growth in tropical/humid countries is thus channeled through a higher probability of drier than normal weather conditions. Accordingly, taking into account the delayed effects of ENSO through weather conditions suggests that El Niño episodes have a negative growth effect in dry areas of the tropical/humid zone. This effect is likely to be persistent as El Niño tends to increase the exposure of those areas to drier conditions. As shown in the sixth column of Table 3 , this result is robust to DK estimates.

Results for arid/temperate countries show that the coefficient on contemporaneous El Niño events is still slightly significant (at only the $10 \%$ level) while the growth effect of SPEI remains positive and significant (column (6) of Table 4). Importantly, La Niña events have a lagged effect on growth through their interaction with weather patterns, which is essentially the reverse of the El Niño effect observed in tropical/humid countries. Indeed, by bringing higher than average precipitation, La Niña causes rainfall to become more intense and wet areas in arid/temperate countries to become wetter, which adversely affects GDP growth. Again, this result is robust to the choice of estimator, confirming that ENSO events also significantly affect the GDP growth of arid/temperate areas through their delayed impacts on weather conditions.

\subsection{Explaining the growth's response to ENSO events: the role of total factor productivity growth}

As ENSO events have persistent effects through weather patterns, they are only slowly absorbed by the economy and should therefore have long-lasting effects. We thus examine whether the previous results on economic growth are driven through Total Factor Productivity (TFP) growth. In order to do this, we reestimate equation (2) with TFP per capita growth (instead of GDP per capita growth). ${ }^{20}$

The results in Table 5 indicate strong evidence that the ENSO events affect TFP growth through their interaction with weather patterns. The predominance of TFP growth for explaining the delayed ENSO effects on output growth is in line with other panel studies that find strong evidence of weather effects on

\footnotetext{
${ }^{20}$ For the definition of TFP see Table A.3 and for the panel unit root tests for annual TFP growth, see Table C.3 in the Appendix.
} 
Table 4: Contemporaneous and lagged impacts of ENSO events Arid \& temperate countries

\begin{tabular}{|c|c|c|c|c|c|c|}
\hline & \multicolumn{3}{|c|}{ PCSE estimates } & \multicolumn{3}{|c|}{ DK estimates } \\
\hline & (1) & (2) & (3) & $(4)$ & (5) & (6) \\
\hline $\mathrm{ONI}_{t} \geq 0$ & $\begin{array}{l}-0.0143^{*} \\
(0.0078)\end{array}$ & $\begin{array}{l}-0.0112 \\
(0.0078)\end{array}$ & $\begin{array}{l}-0.0123 \\
(0.0076)\end{array}$ & $\begin{array}{l}-0.0241^{*} \\
(0.0133)\end{array}$ & $\begin{array}{l}-0.0212^{*} \\
(0.0125)\end{array}$ & $\begin{array}{c}-0.0204 * \\
(0.0119)\end{array}$ \\
\hline $\mathrm{ONI}_{t}<0$ & $\begin{array}{c}0.0007 \\
(0.0088)\end{array}$ & $\begin{array}{c}0.0031 \\
(0.0086)\end{array}$ & $\begin{array}{c}0.0009 \\
(0.0079)\end{array}$ & $\begin{array}{l}-0.0005 \\
(0.0092)\end{array}$ & $\begin{array}{c}0.0019 \\
(0.0091)\end{array}$ & $\begin{array}{c}0.0007 \\
(0.0084)\end{array}$ \\
\hline $\mathrm{SPEI}_{t}$ & & $\begin{array}{c}0.0128^{* * *} \\
(0.0031)\end{array}$ & $\begin{array}{c}0.0150^{* * *} \\
(0.0056)\end{array}$ & & $\begin{array}{c}0.0131^{* *} \\
(0.0056)\end{array}$ & $\begin{array}{c}0.0168^{* * *} \\
(0.0060)\end{array}$ \\
\hline $\mathrm{ONI}_{t-1} \geq 0$ & & & $\begin{array}{l}-0.0095 \\
(0.0075)\end{array}$ & & & $\begin{array}{l}-0.0150 \\
(0.0095)\end{array}$ \\
\hline $\mathrm{ONI}_{t-1}<0$ & & & $\begin{array}{l}-0.0077 \\
(0.0077)\end{array}$ & & & $\begin{array}{l}-0.0068 \\
(0.0130)\end{array}$ \\
\hline $\mathrm{ONI}_{t-1} \geq 0 \times S P E I_{t}$ & & & $\begin{array}{c}0.0105 \\
(0.0093)\end{array}$ & & & $\begin{array}{c}0.0092 \\
(0.0077)\end{array}$ \\
\hline $\mathrm{ONI}_{t-1}<0 \times S P E I_{t}$ & & & $\begin{array}{c}-0.0194^{*} \\
(0.0103)\end{array}$ & & & $\begin{array}{c}-0.0226^{* *} \\
(0.0097)\end{array}$ \\
\hline Constant & $\begin{array}{c}0.0202^{* * *} \\
(0.0054)\end{array}$ & $\begin{array}{c}0.0222^{* * *} \\
(0.0054) \\
\end{array}$ & $\begin{array}{c}0.0268^{* * *} \\
(0.0063)\end{array}$ & $\begin{array}{c}0.0225^{* * *} \\
(0.0072) \\
\end{array}$ & $\begin{array}{c}0.0221^{* * *} \\
(0.0070)\end{array}$ & $\begin{array}{c}0.0271^{* * *} \\
(0.0091) \\
\end{array}$ \\
\hline Countries $(N)$ & 36 & 36 & 36 & 36 & 36 & 36 \\
\hline Observations $(N \times T)$ & 1299 & 1299 & 1299 & 1299 & 1299 & 1299 \\
\hline$R^{2}[$ within $]$ & 0.0641 & 0.0825 & 0.0952 & {$[0.0174]$} & {$[0.0310]$} & {$[0.0462]$} \\
\hline $\operatorname{PSAR}(1)$ & Yes & Yes & Yes & No & No & No \\
\hline $\mathrm{MA}(3)$ & No & No & No & Yes & Yes & Yes \\
\hline
\end{tabular}

TFP growth (Letta and Tol, 2018). Columns (1) and (4) show a less pronounced immediate impact of El Niño on TFP growth in both climate areas. Adding lagged effects of ENSO yields, however, very similar effects as the interaction terms with SPEI are still significant in both areas (columns (3) and (6)). As for economic growth, the analysis by climate regions reveals different delayed growth effects of ENSO events through their connection with weather conditions, with a predominance of negative effects of El Niño events in tropical/humid countries and of La Niña episodes in arid/temperate countries. The negative response of GDP growth to ENSO events is thus mainly driven by the decrease in productivity growth due to the delayed effects of ENSO on weather patterns. This finding is important as it implies that the fall in productivity growth driven by ENSO events is likely to have a persistent negative impact on output growth in subsequent periods and possibly alter income trajectories in a permanent way, especially since it is expected that extreme 
El Niño and La Niña events will become more frequent (IPCC, 2019).

Table 5: Contemporaneous and lagged impacts of ENSO events, TFP growth

\begin{tabular}{|c|c|c|c|c|c|c|}
\hline & \multicolumn{3}{|c|}{ Tropical \& humid countries } & \multicolumn{3}{|c|}{ Arid \& temperate countries } \\
\hline & $(1)$ & $(2)$ & $(3)$ & $(4)$ & $(5)$ & $(6)$ \\
\hline $\mathrm{ONI}_{t} \geq 0$ & $\begin{array}{c}-0.0178^{* * *} \\
(0.0059)\end{array}$ & $\begin{array}{c}-0.0162^{* * *} \\
(0.0059)\end{array}$ & $\begin{array}{c}-0.0207^{*} \\
(0.0106)\end{array}$ & $\begin{array}{l}-0.0080 \\
(0.0075)\end{array}$ & $\begin{array}{l}-0.0063 \\
(0.0073)\end{array}$ & $\begin{array}{l}-0.0062 \\
(0.0073)\end{array}$ \\
\hline $\mathrm{ONI}_{t}<0$ & $\begin{array}{l}-0.0096 \\
(0.0059)\end{array}$ & $\begin{array}{c}-0.0104^{*} \\
(0.0058)\end{array}$ & $\begin{array}{l}-0.0138 \\
(0.0102)\end{array}$ & $\begin{array}{l}-0.0030 \\
(0.0081)\end{array}$ & $\begin{array}{l}-0.0018 \\
(0.0079)\end{array}$ & $\begin{array}{l}-0.0033 \\
(0.0076)\end{array}$ \\
\hline $\mathrm{SPEI}_{t}$ & & $\begin{array}{c}0.0068^{* * *} \\
(0.0022)\end{array}$ & $\begin{array}{l}-0.0055 \\
(0.0066)\end{array}$ & & $\begin{array}{c}0.0107^{* * *} \\
(0.0033)\end{array}$ & $\begin{array}{c}0.0151^{* *} \\
(0.0059)\end{array}$ \\
\hline $\mathrm{ONI}_{t-1} \geq 0$ & & & $\begin{array}{l}-0.0168 \\
(0.0106)\end{array}$ & & & $\begin{array}{l}-0.0089 \\
(0.0072)\end{array}$ \\
\hline $\mathrm{ONI}_{t-1}<0$ & & & $\begin{array}{l}-0.0014 \\
(0.0101)\end{array}$ & & & $\begin{array}{l}-0.0042 \\
(0.0073)\end{array}$ \\
\hline $\mathrm{ONI}_{t-1} \geq 0 \times S P E I_{t}$ & & & $\begin{array}{c}0.0303^{* *} \\
(0.0121)\end{array}$ & & & $\begin{array}{c}0.0063 \\
(0.0095)\end{array}$ \\
\hline $\mathrm{ONI}_{t-1}<0 \times S P E I_{t}$ & & & $\begin{array}{l}0.0222^{*} \\
(0.0134)\end{array}$ & & & $\begin{array}{c}-0.0226^{* *} \\
(0.0114)\end{array}$ \\
\hline Constant & $\begin{array}{c}0.0133 \\
(0.0122)\end{array}$ & $\begin{array}{c}0.0121 \\
(0.0120)\end{array}$ & $\begin{array}{c}0.0215 \\
(0.0176)\end{array}$ & $\begin{array}{c}0.0057 \\
(0.0059)\end{array}$ & $\begin{array}{c}0.0078 \\
(0.0060)\end{array}$ & $\begin{array}{c}0.0109 \\
(0.0067)\end{array}$ \\
\hline Countries $(N)$ & 30 & 30 & 30 & 30 & 30 & 30 \\
\hline Observations $(N \times T)$ & 1135 & 1135 & 1135 & 1058 & 1058 & 1058 \\
\hline$R^{2}$ & 0.0463 & 0.0535 & 0.0460 & 0.0236 & 0.0359 & 0.0482 \\
\hline $\operatorname{PSAR}(1)$ & Yes & Yes & Yes & Yes & Yes & Yes \\
\hline
\end{tabular}

Note: Prais-Winsten (PSCE) estimates. ONI $\geq 0$ and $O N I<0$ stand respectively for El Niño and La Niña conditions. Standard errors are in parentheses. ${ }^{* * *},{ }^{* *}$, and ${ }^{*}$ indicate respectively $1 \%, 5 \%$, and $10 \%$ significance levels. PSAR(1) stands for panel specific AR(1)-type autocorrelation.

\section{ENSO extreme events and duration of weather patterns}

In this section we provide evidence for the robustness of our results when accounting for ENSO extreme events and the possible influence of the duration of weather patterns. But first we check the robustness of our results to different measures of income and ENSO events. For example, as an alternate measure of income, we make use of GDP per capita series from the World Bank's World Development Indicators and as another measure of ENSO, we use the Equatorial Southern Oscillation Index (SOI), calculated as the standardized anomaly of the difference between the area-average monthly sea level pressure in an area of the eastern equatorial Pacific $\left(80^{\circ} \mathrm{W}-130^{\circ} \mathrm{W}, 5^{\circ} \mathrm{N}-5^{\circ} \mathrm{S}\right)$ and an area over Indonesia $\left(90^{\circ} \mathrm{E}-140^{\circ} \mathrm{E}, 5 \mathrm{~N}-5^{\circ} \mathrm{S}\right)$. The results with these alternative measures illustrate that no matter which measure is utilized, the interaction term between ENSO events and weather conditions remains significant and has the same sign with the same order of magnitude 
for both climate areas. This finding is not surprising, given the high correlation between the two GDP per capita growth series and the two ENSO indexes. ${ }^{21}$ For the sake of brevity, the results of these robustness checks are not reported in the paper but are available from the authors upon request. Finally, consistent with the estimation approach adopted in the growth literature, we estimated equation (2) using the system GMM estimator. The results, reported in Table C.4 of the Appendix, provide clear evidence of delayed growth impacts of ENSO through weather conditions.

\subsection{Accounting for ENSO extreme events}

As mentioned before, it is not clear whether the analysis of the asymmetric effects of the ENSO phases through the introduction of a Heaviside indicator fully captures the occurrence of extreme events. For example, years 1988 and 2010 show average values of $\mathrm{ONI}$ equal to $-0.56^{\circ} \mathrm{C}$ and $-0.19^{\circ} \mathrm{C}$, respectively. Despite these low average negative values, these years are nevertheless characterized by the occurrence of La Niña events since during these two years ONI values lower than $-1^{\circ} \mathrm{C}$ were observed during at least five consecutive months. By contrast, other years exhibit larger negative values of ONI but are characterized by neutral ENSO conditions due to the short duration of these anomalies. To address this issue, we use a specification that includes categorical variables - instead of a Heaviside indicator - to account more adequately for the different phases associated with ENSO (El Niño, La Niña or neutral phases):

$$
\Delta y_{i, t}=\lambda+\alpha E N S O_{t}+\beta S P E I_{i, t}+\gamma E N S O_{t-1}+\delta\left(E N S O_{t-1} \times S P E I_{i, t}\right)+\mu_{i}+\varepsilon_{i, t}
$$

where $E N S O_{t}$ is a categorical variable defined by annualized ONI anomalies in year $t$ such that: ${ }^{22}$

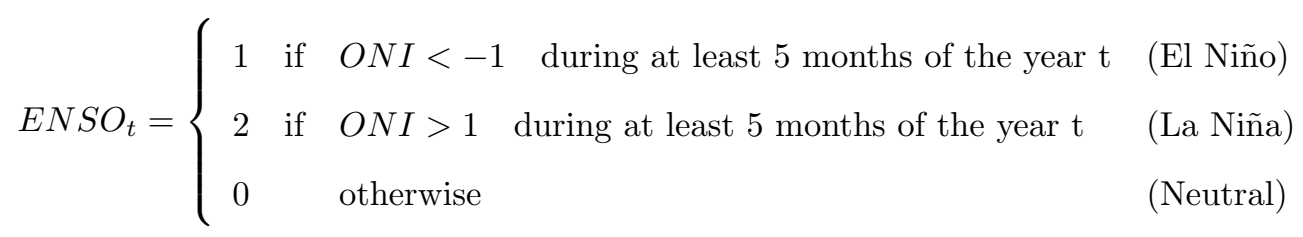

Neutral episodes are then the excluded episodes, so that the coefficients on La Niña and El Niño events must be interpreted differently than those in Equation (2). Indeed, the coefficients now measure the growth effect differential of La Niña and/or El Niño relative to neutral episodes, instead of analyzing the growth effects of ENSO according to the positive or the negative values taken by the variable ONI.

The estimation results of Equation (3) are reported in Table 6. We first notice that taking into account the

\footnotetext{
${ }^{21}$ See Table A.2 and Figure A.2 in the Appendix.

${ }^{22}$ We have calculated the polychoric correlation coefficient between the ONI variable and dummy variables taking the value 1 in case of El Niño/La Niña events and 0 otherwise. The correlation between ONI and the dummy variable that captures El Niño is high (0.91) while the correlation with La Niña events is smaller (-0.76).
} 
duration and magnitude in the definition of ENSO does significantly change its estimated contemporaneous impact. Of particular importance is strong evidence of a more significant impact of El Niño in arid/temperate countries, suggesting a high sensibility of this climate zone to the intensities of this ENSO regime. Thus, compared to normal episodes, El Niño events seem to be now associated with lower growth rates in both climate areas. In contrast, and consistent with our previous results, La Niña events are not significantly different from normal ones for both climate areas. As can be seen, adding the delayed effects of ENSO on weather conditions does not significantly change the coefficient of the interaction term in tropical/humid countries (column (3)). Indeed estimates for this climate area show similar results to previous ones. El Niño events are growth limiting by bringing unusual warmth in tropical/humid countries already experiencing dry conditions. Similarly, the use of this new measure of ENSO events confirms that La Niña, by causing increased rainfall, has a negative and lagged growth effect in arid/temperate areas with already wet conditions (column (6)). Overall, these findings support our main hypothesis related to the importance of local weather conditions when assessing the growth effects of ENSO cycles.

Table 6: Contemporaneous and lagged impacts of ENSO events (dummy variables)

\begin{tabular}{|c|c|c|c|c|c|c|}
\hline & \multicolumn{3}{|c|}{ Tropical \& humid countries } & \multicolumn{3}{|c|}{ Arid \& temperate countries } \\
\hline & (1) & $(2)$ & (3) & $(4)$ & (5) & (6) \\
\hline $\mathrm{El} \mathrm{Niño} t$ & $\begin{array}{c}-0.0068^{*} \\
(0.0039)\end{array}$ & $\begin{array}{c}-0.0061 \\
(0.0038)\end{array}$ & $\begin{array}{c}-0.0080^{* *} \\
(0.0040)\end{array}$ & $\begin{array}{c}-0.0120^{* *} \\
(0.0053)\end{array}$ & $\begin{array}{c}-0.0139^{* *} \\
(0.0058)\end{array}$ & $\begin{array}{c}-0.0125^{* * *} \\
(0.0048)\end{array}$ \\
\hline La Niñat & $\begin{array}{c}0.0019 \\
(0.0043)\end{array}$ & $\begin{array}{c}0.0015 \\
(0.0042)\end{array}$ & $\begin{array}{c}0.0014 \\
(0.0042)\end{array}$ & $\begin{array}{c}0.0055 \\
(0.0056)\end{array}$ & $\begin{array}{c}0.0037 \\
(0.0064)\end{array}$ & $\begin{array}{c}0.0060 \\
(0.0051)\end{array}$ \\
\hline $\mathrm{SPEI}_{t}$ & & $\begin{array}{c}0.0047^{* *} \\
(0.0021)\end{array}$ & $\begin{array}{c}0.0001 \\
(0.0030)\end{array}$ & & $\begin{array}{c}0.0136^{* * *} \\
(0.0035)\end{array}$ & $\begin{array}{c}0.0154^{* * *} \\
(0.0045)\end{array}$ \\
\hline El Niñot-1 & & & $\begin{array}{l}-0.0043 \\
(0.0041)\end{array}$ & & & $\begin{array}{l}-0.0065 \\
(0.0052)\end{array}$ \\
\hline La Niña $a_{t-1}$ & & & $\begin{array}{l}-0.0043 \\
(0.0041)\end{array}$ & & & $\begin{array}{l}-0.0059 \\
(0.0050)\end{array}$ \\
\hline El Niño ${ }_{t-1} \times S P E I_{t}$ & & & $\begin{array}{c}0.0117^{* *} \\
(0.0049)\end{array}$ & & & $\begin{array}{c}0.0069 \\
(0.0071)\end{array}$ \\
\hline La Niña ${ }_{t-1} \times S P E I_{t}$ & & & $\begin{array}{c}0.0042 \\
(0.0053)\end{array}$ & & & $\begin{array}{c}-0.0175^{* * *} \\
(0.0066)\end{array}$ \\
\hline Constant & $\begin{array}{c}0.0141 \\
(0.0131) \\
\end{array}$ & $\begin{array}{c}0.0133 \\
(0.0129) \\
\end{array}$ & $\begin{array}{c}0.0162 \\
(0.0130) \\
\end{array}$ & $\begin{array}{c}0.0188^{* * *} \\
(0.0047) \\
\end{array}$ & $\begin{array}{c}0.0228^{* * *} \\
(0.0059) \\
\end{array}$ & $\begin{array}{c}0.0254^{* * *} \\
(0.0050) \\
\end{array}$ \\
\hline Countries $(N)$ & 39 & 39 & 39 & 36 & 36 & 36 \\
\hline Observations $(N \times T)$ & 1521 & 1521 & 1521 & 1299 & 1299 & 1299 \\
\hline$R^{2}$ & 0.0717 & 0.0742 & 0.0809 & 0.0744 & 0.0835 & 0.108 \\
\hline $\operatorname{PSAR}(1)$ & Yes & Yes & Yes & Yes & Yes & Yes \\
\hline
\end{tabular}

Note: Prais-Winsten (PSCE) estimates. Standard errors are in parentheses. ${ }^{* * *},{ }^{* *}$, and $^{*}$ indicate respectively 1\%, 5\%, and 10\% significance levels. PSAR(1) stands for panel specific AR(1)-type autocorrelation. 


\subsection{The influence of weather patterns}

We have used so far, as benchmark variable, the 6-month SPEI as it is usually considered as the most appropriate index when addressing events occurring at the agricultural season level (Vicente-Serrano et al., 2010, 2011). As demonstrated by McKee et al. (1993), water surplus/deficits can accumulate over time and impact differently usable water resources. Several studies have shown that the responses of soil moisture, river discharge, reservoir storage, vegetation activity and crop production can vary markedly as a function of the time scale (McKee et al., 1993; Vicente-Serrano et al., 2010; Beguería et al., 2014). It is then essential to control for the time scale over which weather conditions accumulate since the growth response to hydroclimatic conditions, and thus indirectly to ENSO events, can also vary as a function of time. ${ }^{23}$ Accordingly, we re-estimate Equations (2) and (3) using 3-month and 12-month SPEI. Using shorter time scales such as the 3-month SPEI can better reflect the impacts of ENSO on economic growth through short bursts of heavy rain or droughts. We also control for a longer time scale (12-month SPEI) since shorter extreme weather events may in some instances only be visible over a longer period, and thus not be necessarily detected over a 3-month period. ${ }^{24}$ Tables 7 and 8 present the results of specifications (2) and (3) respectively incorporating these new values of SPEI.

Several notable points emerge from these results. First, using the 3-month and 12-month SPEI does not change our results, providing further evidence for the robustness of our results and the importance of taking into account local weather conditions. However, the magnitude of this impact varies as a function of the time scale over which weather conditions accumulate. In particular, it is more pronounced at shorter time scales, i.e. for weather events that possibly begin and end rapidly. Using the 3-month SPEI leads to stronger adverse effects of La Niña, the year following its occurrence, in wet areas of the arid/temperate zone. Similarly, El Niño events are associated with a deeper persistent effect on the GDP growth of dry areas with a tropical/arid climate when considering shorter time scales, suggesting that the influence of ENSO on droughts is weakened at longer time scales in this climate area.

\footnotetext{
${ }^{23}$ Beside the time-scales over which weather patterns can be quantified, a number of studies have pointed out that the way economies adjust to hydro-meteorological conditions depends on the intensity of weather events (Burke et al., 2015). To address this issue, we have also estimated Equations (2) and (3) by adding a quadratic specification in the weather variable deemed to reflect extreme weather conditions. Results suggest no change in our main conclusions. For the sake of brevity, we do not report these results. They are available from the authors upon request.

${ }^{24}$ This happens, for example, when a short-term extreme event is bounded by relatively normal periods.
} 
Table 7: Accounting for the duration of weather conditions (heaviside variable)

\begin{tabular}{|c|c|c|c|c|c|c|c|c|}
\hline & \multicolumn{4}{|c|}{ 12-month SPEI } & \multicolumn{4}{|c|}{ 3-month SPEI } \\
\hline & \multicolumn{2}{|c|}{ Tropical \& humid } & \multicolumn{2}{|c|}{ Arid \& temperate } & \multicolumn{2}{|c|}{ Tropical \& humid } & \multicolumn{2}{|c|}{ Arid \& temperate } \\
\hline & (1) & $(2)$ & $(3)$ & $(4)$ & $(5)$ & $(6)$ & (7) & (8) \\
\hline $\mathrm{ONI}_{t} \geq 0$ & $\begin{array}{c}-0.0116^{* *} \\
(0.0054)\end{array}$ & $\begin{array}{c}-0.0160^{* * *} \\
(0.0056)\end{array}$ & $\begin{array}{c}-0.0157^{*} \\
(0.0084)\end{array}$ & $\begin{array}{c}-0.0183^{* *} \\
(0.0089)\end{array}$ & $\begin{array}{c}-0.0121^{* *} \\
(0.0059)\end{array}$ & $\begin{array}{c}-0.0143^{* * *} \\
(0.0055)\end{array}$ & $\begin{array}{c}-0.0163^{*} \\
(0.0086)\end{array}$ & $\begin{array}{c}-0.0197^{* *} \\
(0.0089)\end{array}$ \\
\hline $\mathrm{ONI}_{t}<0$ & $\begin{array}{l}-0.0035 \\
(0.0055)\end{array}$ & $\begin{array}{l}-0.0055 \\
(0.0055)\end{array}$ & $\begin{array}{c}0.0028 \\
(0.0096)\end{array}$ & $\begin{array}{c}0.0006 \\
(0.0095)\end{array}$ & $\begin{array}{l}-0.0026 \\
(0.0059)\end{array}$ & $\begin{array}{l}-0.0061 \\
(0.0054)\end{array}$ & $\begin{array}{c}0.0036 \\
(0.0098)\end{array}$ & $\begin{array}{c}0.0003 \\
(0.0094)\end{array}$ \\
\hline $\mathrm{SPEI}_{t}$ & $\begin{array}{c}0.0015 \\
(0.0017)\end{array}$ & $\begin{array}{c}-0.0048^{*} \\
(0.0028)\end{array}$ & $\begin{array}{c}0.0106^{* * *} \\
(0.0028)\end{array}$ & $\begin{array}{c}0.0138^{* * *} \\
(0.0043)\end{array}$ & $\begin{array}{c}0.0056^{* *} \\
(0.0027)\end{array}$ & $\begin{array}{c}0.0018 \\
(0.0032)\end{array}$ & $\begin{array}{c}0.0128^{* * *} \\
(0.0043)\end{array}$ & $\begin{array}{c}0.0206^{* * *} \\
(0.0054)\end{array}$ \\
\hline $\mathrm{ONI}_{t-1} \geq 0$ & & $\begin{array}{c}-0.0099^{*} \\
(0.0056)\end{array}$ & & $\begin{array}{l}-0.0133 \\
(0.0090)\end{array}$ & & $\begin{array}{c}-0.0110^{* *} \\
(0.0055)\end{array}$ & & $\begin{array}{l}-0.0135 \\
(0.0090)\end{array}$ \\
\hline $\mathrm{ONI}_{t-1}<0$ & & $\begin{array}{l}-0.0081 \\
(0.0053)\end{array}$ & & $\begin{array}{l}-0.0067 \\
(0.0090)\end{array}$ & & $\begin{array}{l}-0.0070 \\
(0.0052)\end{array}$ & & $\begin{array}{l}-0.0076 \\
(0.0091)\end{array}$ \\
\hline $\mathrm{ONI}_{t-1} \geq 0 \times S P E I_{t}$ & & $\begin{array}{c}0.0146^{* * *} \\
(0.0052)\end{array}$ & & $\begin{array}{c}0.0025 \\
(0.0085)\end{array}$ & & $\begin{array}{c}0.0156^{* *} \\
(0.0075)\end{array}$ & & $\begin{array}{l}-0.0019 \\
(0.0096)\end{array}$ \\
\hline $\mathrm{ONI}_{t-1}<0 \times S P E I_{t}$ & & $\begin{array}{l}0.0090^{*} \\
(0.0054)\end{array}$ & & $\begin{array}{c}-0.0139^{*} \\
(0.0075)\end{array}$ & & $\begin{array}{c}0.0056 \\
(0.0078)\end{array}$ & & $\begin{array}{c}-0.0282^{* *} \\
(0.0119)\end{array}$ \\
\hline Constant & $\begin{array}{c}0.0167 \\
(0.0165)\end{array}$ & $\begin{array}{c}0.0227 \\
(0.0170)\end{array}$ & $\begin{array}{c}0.0236^{* * *} \\
(0.0071)\end{array}$ & $\begin{array}{c}0.0281^{* * *} \\
(0.0087)\end{array}$ & $\begin{array}{c}0.0162 \\
(0.0163)\end{array}$ & $\begin{array}{c}0.0221 \\
(0.0166)\end{array}$ & $\begin{array}{c}0.0219^{* * *} \\
(0.0068)\end{array}$ & $\begin{array}{c}0.0283^{* * *} \\
(0.0083)\end{array}$ \\
\hline Countries $(N)$ & 39 & 39 & 36 & 36 & 39 & 39 & 36 & 36 \\
\hline Observations $(N \times T)$ & 1521 & 1521 & 1299 & 1299 & 1521 & 1521 & 1299 & 1299 \\
\hline$R^{2}$ & 0.0960 & 0.1050 & 0.0736 & 0.0863 & 0.0986 & 0.1060 & 0.0687 & 0.0807 \\
\hline $\operatorname{PSAR}(1)$ & Yes & Yes & Yes & Yes & Yes & Yes & Yes & Yes \\
\hline
\end{tabular}

Note: Prais-Winsten (PSCE) estimates. Standard errors are in parentheses. ${ }^{* * *},{ }^{* *}$, and $^{*}$ indicate respectively $1 \%$, $5 \%$, and $10 \%$ significance levels. PSAR(1) stands for panel specific AR(1)-type autocorrelation.

In order to illustrate how the growth effects of ENSO propagate throughout the time scale and for different hydrological conditions, we estimate its marginal growth effects at different levels and time-scales of SPEI. Figures 4 and 5 depict the marginal effect of ENSO phases at time $t-1$ on GDP growth as estimated from regressions (2) and (3) respectively. 
Table 8: Accounting for the duration of weather conditions (dummy variable)

\begin{tabular}{|c|c|c|c|c|c|c|c|c|}
\hline & \multicolumn{4}{|c|}{ 12-month SPEI } & \multicolumn{4}{|c|}{ 3-month SPEI } \\
\hline & \multicolumn{2}{|c|}{ Tropical \& humid } & \multicolumn{2}{|c|}{ Arid \& temperate } & \multicolumn{2}{|c|}{ Tropical \& humid } & \multicolumn{2}{|c|}{ Arid \& temperate } \\
\hline & (1) & $(2)$ & $(3)$ & (4) & $(5)$ & (6) & (7) & $(8)$ \\
\hline $\mathrm{El} \mathrm{Niño} \mathrm{o}_{t}$ & $\begin{array}{c}-0.0065^{*} \\
(0.0039)\end{array}$ & $\begin{array}{c}-0.0085^{* *} \\
(0.0040)\end{array}$ & $\begin{array}{c}-0.0136^{* *} \\
(0.0058)\end{array}$ & $\begin{array}{c}-0.0161^{* * *} \\
(0.0056)\end{array}$ & $\begin{array}{l}-0.0062 \\
(0.0038)\end{array}$ & $\begin{array}{c}-0.0081^{* *} \\
(0.0040)\end{array}$ & $\begin{array}{c}-0.0117^{* *} \\
(0.0053)\end{array}$ & $\begin{array}{r}-0.0130^{* * *} \\
(0.0049)\end{array}$ \\
\hline La Niña ${ }_{t}$ & $\begin{array}{c}0.0017 \\
(0.0043)\end{array}$ & $\begin{array}{c}0.0017 \\
(0.0043)\end{array}$ & $\begin{array}{c}0.0035 \\
(0.0063)\end{array}$ & $\begin{array}{c}0.0053 \\
(0.0061)\end{array}$ & $\begin{array}{c}0.0013 \\
(0.0042)\end{array}$ & $\begin{array}{c}0.0011 \\
(0.0042)\end{array}$ & $\begin{array}{c}0.0059 \\
(0.0056)\end{array}$ & $\begin{array}{c}0.0062 \\
(0.0052)\end{array}$ \\
\hline $\mathrm{SPEI}_{t}$ & $\begin{array}{c}0.0022 \\
(0.0018)\end{array}$ & $\begin{array}{l}-0.0024 \\
(0.0025)\end{array}$ & $\begin{array}{c}0.0105^{* * *} \\
(0.0028)\end{array}$ & $\begin{array}{c}0.0125^{* * *} \\
(0.0039)\end{array}$ & $\begin{array}{c}0.0057^{* *} \\
(0.0026)\end{array}$ & $\begin{array}{c}0.0013 \\
(0.0032)\end{array}$ & $\begin{array}{c}0.0127^{* * *} \\
(0.0039)\end{array}$ & $\begin{array}{c}0.0152^{* * *} \\
(0.0055)\end{array}$ \\
\hline $\mathrm{El} \mathrm{Niño}{ }_{t-1}$ & & $\begin{array}{l}-0.0039 \\
(0.0041)\end{array}$ & & $\begin{array}{c}-0.0094 \\
(0.0061)\end{array}$ & & $\begin{array}{l}-0.0049 \\
(0.0041)\end{array}$ & & $\begin{array}{l}-0.0063 \\
(0.0052)\end{array}$ \\
\hline La Niña ${ }_{t-1}$ & & $\begin{array}{l}-0.0042 \\
(0.0041)\end{array}$ & & $\begin{array}{l}-0.0046 \\
(0.0059)\end{array}$ & & $\begin{array}{l}-0.0041 \\
(0.0040)\end{array}$ & & $\begin{array}{l}-0.0056 \\
(0.0051)\end{array}$ \\
\hline El $\mathrm{Niño}_{t-1} \times S P E I_{t}$ & & $\begin{array}{c}0.0120^{* * *} \\
(0.0038)\end{array}$ & & $\begin{array}{c}0.0038 \\
(0.0063)\end{array}$ & & $\begin{array}{c}0.0142^{* *} \\
(0.0060)\end{array}$ & & $\begin{array}{c}0.0108 \\
(0.0095)\end{array}$ \\
\hline La Niña ${ }_{t-1} \times S P E I_{t}$ & & $\begin{array}{c}0.0041 \\
(0.0045)\end{array}$ & & $\begin{array}{l}-0.0091^{*} \\
(0.0055)\end{array}$ & & $\begin{array}{c}0.0063 \\
(0.0064)\end{array}$ & & $\begin{array}{c}-0.0197^{* *} \\
(0.0084)\end{array}$ \\
\hline Constant & $\begin{array}{c}0.0136 \\
(0.0130) \\
\end{array}$ & $\begin{array}{c}0.0158 \\
(0.0131) \\
\end{array}$ & $\begin{array}{c}0.0233^{* * *} \\
(0.0062)\end{array}$ & $\begin{array}{c}0.0264^{* * * *} \\
(0.0070) \\
\end{array}$ & $\begin{array}{c}0.0134 \\
(0.0129) \\
\end{array}$ & $\begin{array}{c}0.0166 \\
(0.0129) \\
\end{array}$ & $\begin{array}{c}0.0209^{* * *} \\
(0.0047) \\
\end{array}$ & $\begin{array}{c}0.0247^{* * *} \\
(0.0051)\end{array}$ \\
\hline Countries $(N)$ & 39 & 39 & 36 & 36 & 39 & 39 & 36 & 36 \\
\hline Observations $(N \times T)$ & 1521 & 1521 & 1299 & 1299 & 1521 & 1521 & 1299 & 1299 \\
\hline$R^{2}$ & 0.0725 & 0.0816 & 0.0813 & 0.0927 & 0.0741 & 0.0826 & 0.0879 & 0.102 \\
\hline $\operatorname{PSAR}(1)$ & Yes & Yes & Yes & Yes & Yes & Yes & Yes & Yes \\
\hline
\end{tabular}

Note: Prais-Winsten (PSCE) estimates. Standard errors are in parentheses. ${ }^{* * *},{ }^{* *}$, and ${ }^{*}$ indicate respectively $1 \%$, $5 \%$, and $10 \%$ significance levels. PSAR(1) stands for panel specific AR(1)-type autocorrelation.

As can be seen, in tropical and humid countries, the marginal growth effect of the El Niño variable is clearly different from zero at all negative SPEI (dry conditions) while for positive SPEI (wet conditions), it is close to zero. When wet conditions prevail, El Niño has no effect on growth, while at drier temperatures, by inducing, with some delay, deficits in rainfall, it leads to significantly lower growth rates. The effect becomes weaker as the time scale of the SPEI gets progressively longer. In contrast, La Niña has no significant growth effects regardless of different SPEI values. These findings hold for both specifications using the Heaviside indicator or the dummy variable. For arid and temperate countries, the marginal growth effect of El Niño is not significant. However, the marginal growth effect of La Niña is significantly negative when wet conditions prevail (i.e. for positive values of the SPEI) and loses its significance as weather conditions become drier. This last finding confirms that La Niña, by bringing heavier precipitation in arid/temperate countries, leads to significantly lower growth when wet weather conditions prevail. Again this effect is less pronounced as the time scale of the SPEI gets progressively longer. 
Figure 4: Marginal effect of lagged ONI

(a) Tropical \& humid countries
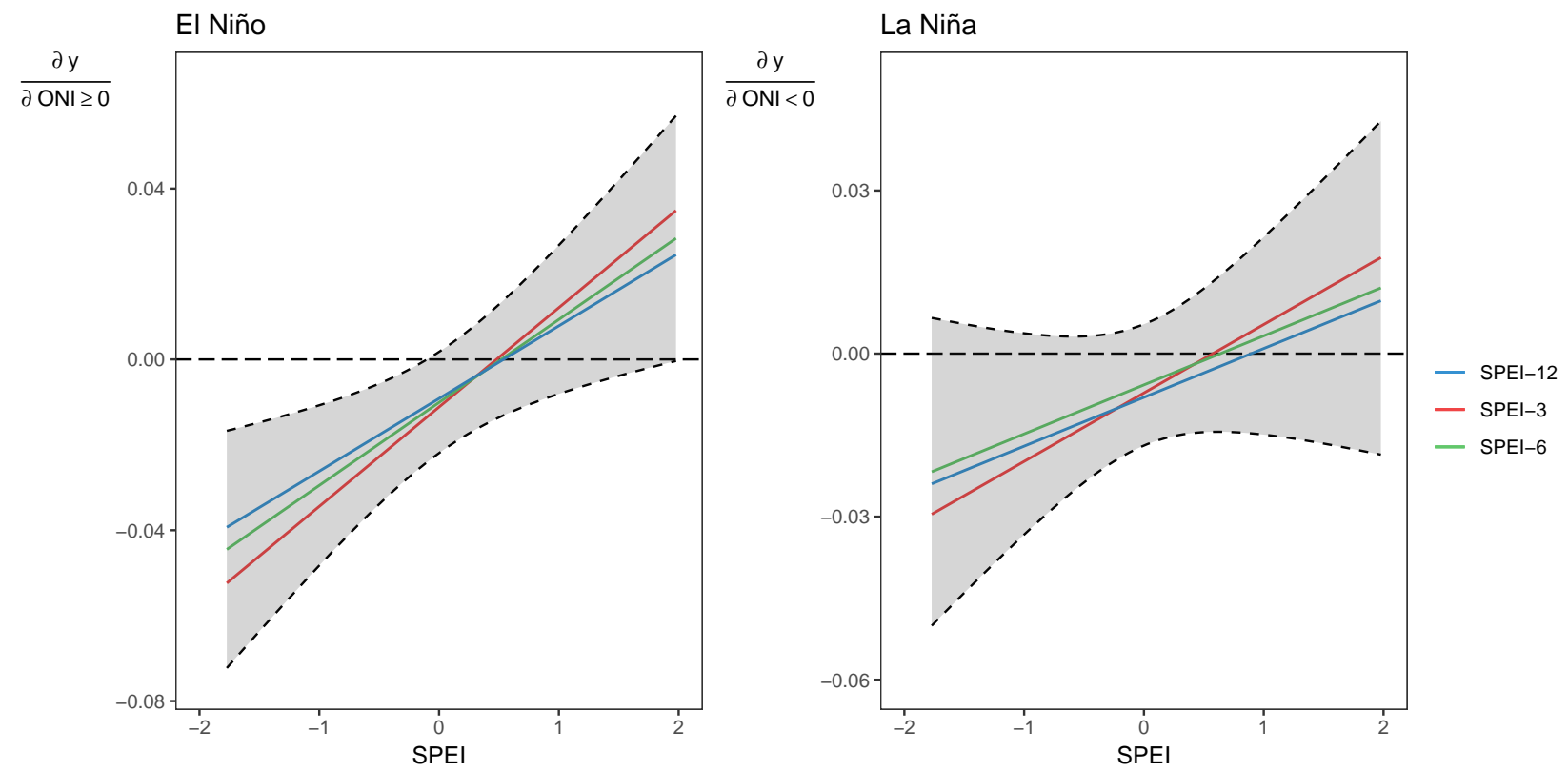

(b) Arid \& temperate countries
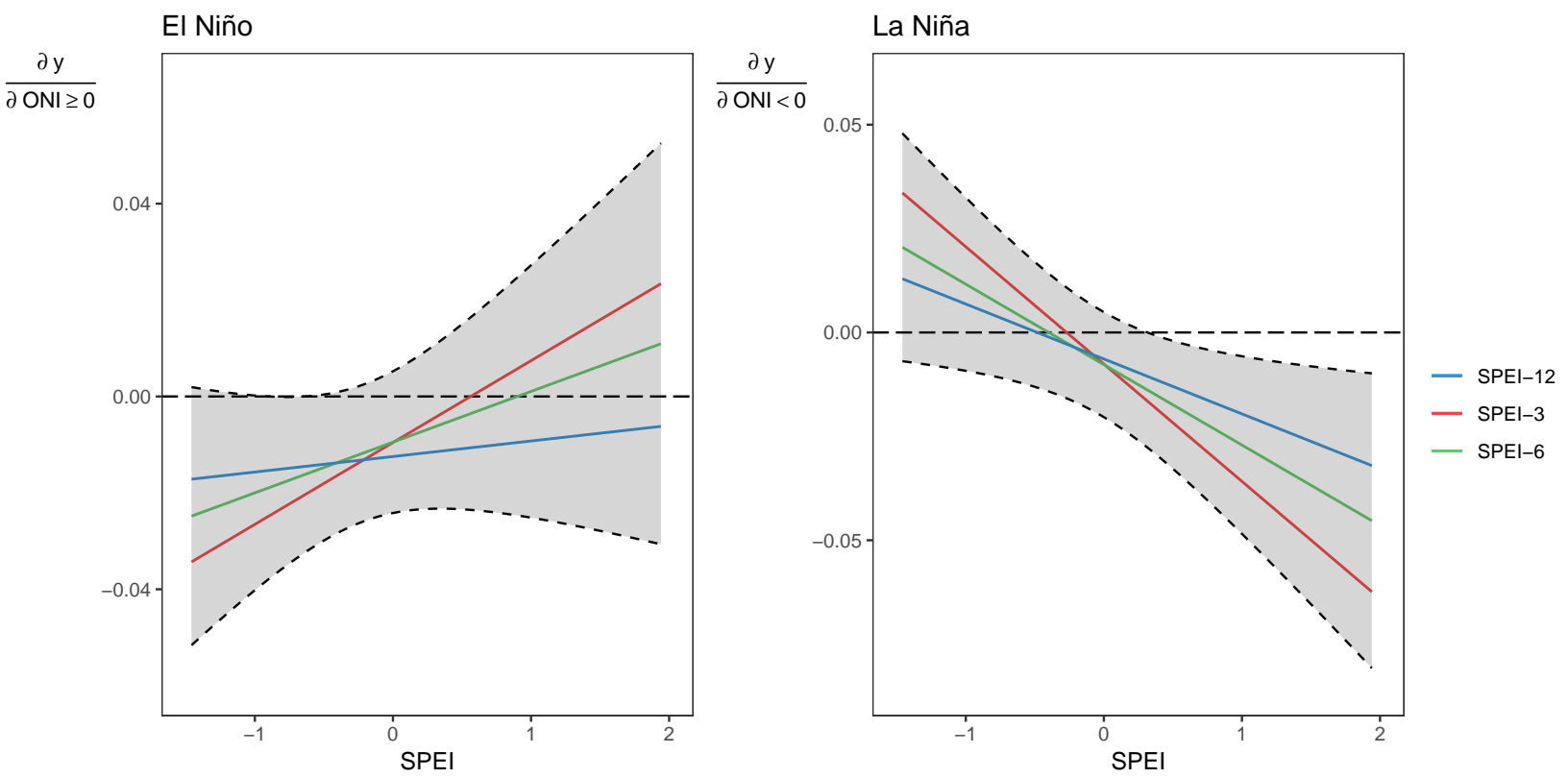

Note: Solid lines report derivatives of the growth response with respect to changes in $O N I_{t-1} I\left(O N I_{t-1} \geq 0\right)$ (El Niño phases) and $O N I_{t-1} I\left(O N I_{t-1}<0\right)$ (La Niña phases). Shaded areas represent $95 \%$ confidence intervals for the benchmark specification using the SPEI-6 month variable. 
Figure 5: Marginal effects of lagged ENSO shocks

(a) Tropical \& humid countries
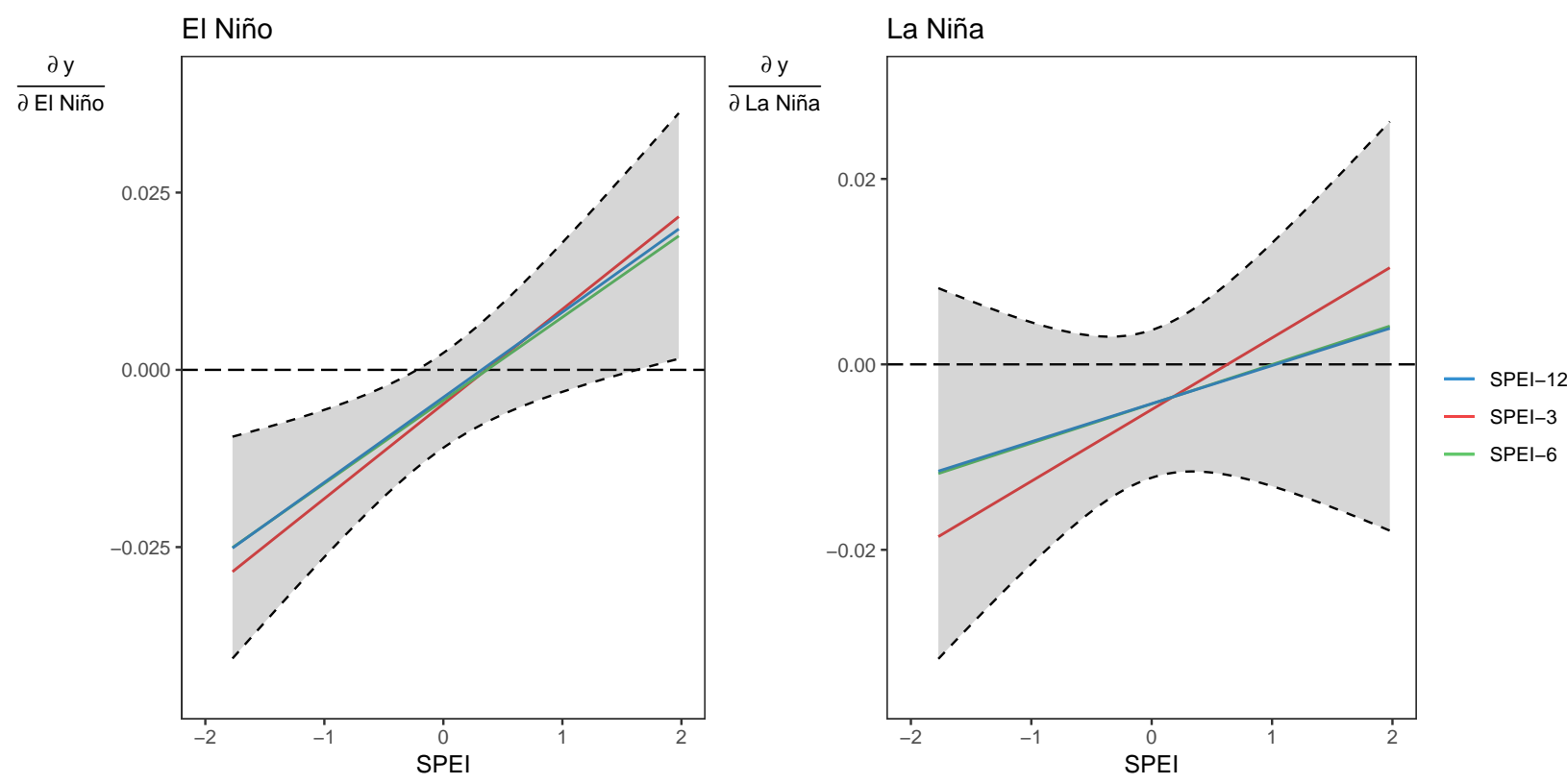

(b) Arid \& temperate countries
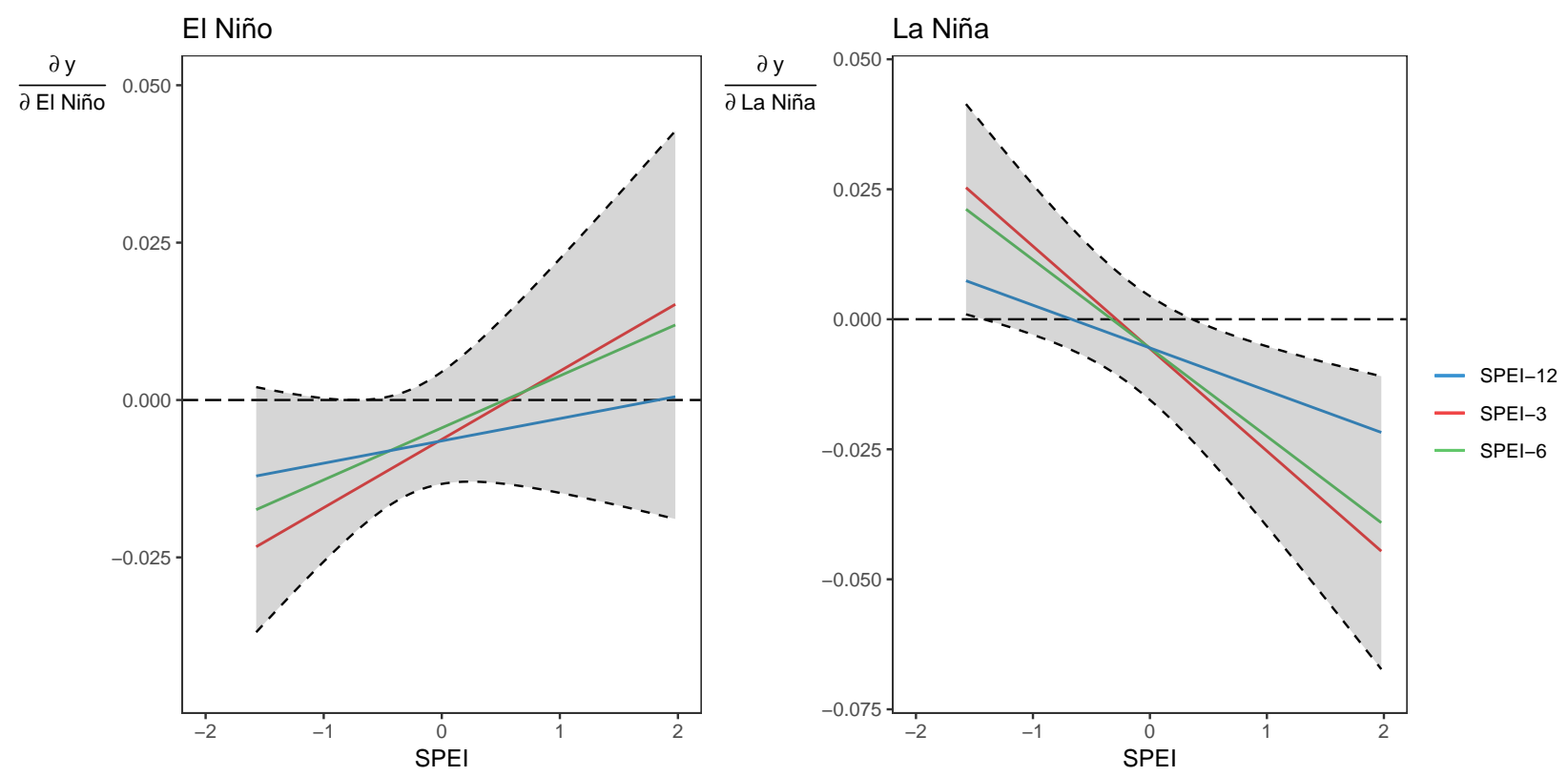

Note: Solid lines report derivatives of the growth response with respect to discrete change from neutral regime to El Niño (La Niña) regime. Shaded areas represent 95\% confidence intervals for the benchmark specification using the SPEI-6 month variable. 


\section{Concluding remarks}

In this paper, we investigated the economic consequences of ENSO events using a sample of 75 countries over the period 1975-2014. We contributed to the existing literature in several respects. First, we analyzed the role of weather patterns in influencing the transmission of global climate cycles to economic growth. We addressed a number of empirical challenges that researchers face when studying the climate-growth nexus, by taking into account the heterogeneous and cumulative effects of weather patterns on economic activity. Second, we provided evidence for asymmetry and nonlinearity in the global influence of ENSO on economic growth by distinguishing weak from moderate to strong El Niño and La Niña events. Third, by also focusing on total factor productivity growth, our analysis shed some light on the long-lasting effects of ENSO events.

We showed that ENSO events have sizeable and persistent economic effects through their interactions with weather patterns in both tropical/humid and arid/temperate countries. In particular, El Niño regimes impact, with some delay, the GDP growth of dry areas in the tropical/humid zone by increasing their sensibility to wet conditions through a higher probability of drier than normal weather conditions. This lagged impact of El Niño on economic growth can be explained by its role in the occurrence of tropical droughts. In contrast, wet areas with an arid/temperate climate are found to be particularly vulnerable to La Niña events. Teleconnection patterns between La Niña and the weather in the arid/temperate zone favor higher than average precipitation that adversely affects economic growth in wet parts of this climate area. Moreover, we illustrated that there is a strong and monotonic relationship between the growth effects of ENSO and the time scales of weather patterns, this relationship being more pronounced over shorter time scales.

These findings are independent of how the asymmetric effects of ENSO are calculated. Indeed, these results hold if we consider two phases of the ENSO cycle measured by positive (El Niño) or negative (La Niña) SSTs anomalies or if we consider a neutral regime and two extreme regimes (El Niño or La Niña) defined according to their magnitude and duration. We also provided strong evidence that ENSO events affect total factor productivity growth through their interaction with weather patterns. This last finding has important implications. As productivity growth is reduced due to the delayed effects of ENSO on weather patterns, this fall is likely to have a persistent negative impact on output growth in subsequent periods and possibly permanently alter income trajectories.

Overall, our results provide new evidence about the growth effects of both El Niño and La Niña, and suggest that a careful assessment of the complex linkages between climate shocks and growth is necessary. Indeed, studies focusing exclusively on the direct impacts of ENSO are likely to mask other essential dimensions of climate variability, such as the asymmetry in hydro-meteorological responses (predominance of wet or humid conditions), or the duration of weather conditions which we showed had important consequences. 
Therefore, the relationship between ENSO events and economic growth is not only explained by the type of climate, but local weather conditions matter too.

In this respect, this paper, by analyzing the weather channel through which ENSO events impact economic growth, reproduced some of the stylized facts raised by the climate literature and in so doing, contributed to a better understanding of the causal mechanisms that underlie the variations in the growth effects of ENSO over time and across countries. By providing evidence for spatial heterogeneity, time persistence and non-linearity in ENSO effects, our study can ultimately contribute to improve early warning systems against extreme weather and make adaptation more efficient, particularly in developing countries whose economies rely heavily on the agricultural sector. These concerns are becoming even more pressing since climate change is expected to further increase the strength of teleconnection patterns associated with ENSO events. 


\section{References}

Aiken, C.M., Santoso, A., McGregor, S., England, M.H., 2013. The 1970's shift in ENSO dynamics: A linear inverse model perspective. Geophysical Research Letters 40, 1612-1617. https://doi.org/10.1002/grl.50264

An, S.I., Jin, F.F., 2004. Nonlinearity and Asymmetry of ENSO. Journal of Climate 17, 2399-2412. https://doi.org/10.1175/1520-0442(2004)017<C2399:NAAOE>2.0.CO;2

An, S.I., Krebs, U., Goose, H., Timmermann, A., 2005. ENSO Suppression due to Weakening of the North Atlantic Thermohaline Circulation. Journal of Climate 18, 3122-3139. https://doi.org/10.1175/jcli3495.1

An, S.I., Wang, B., 2000. Interdecadal Change of the Structure of the ENSO Mode and Its impact on the ENSO Frequency. Journal of Climate 13, 2044-2055.

https://doi.org/10.1175/1520-0442(2000)013<C2044:ICOTSO>2.0.CO;2

Auffhammer, M., Hsiang, S.M., Schlenker, W., Sobel, A., 2013. Using Weather Data and Climate Model Output in Economic Analyses of Climate Change. Review of Environmental Economics and Policy 7, 181-198. https://doi.org/10.1093/reep/ret016

Bamston, A.G., Chelliah, M., B., G.S., 1997. Documentation of a highly ENSO-related SST region in the equatorial pacific: Research note. Atmosphere-Ocean 35(3), 367-383.

https://doi.org/10.1080/07055900.1997.9649597

Beck, N., Katz, J.N., 1995. What To Do (and Not To Do) With Time-Series Cross-Section Data. The American Political Science Review 89(3), 634-647. https://doi.org/10.2307/2082979

Beguería, S., Vicente-Serrano, S.M., Reig, F., Latorre, B., 2014. Standardized precipitation evapotranspiration index (SPEI) revisited: parameter fitting, evapotranspiration models, tools, datasets and drought monitoring. International Journal of Climatology 34, 3001-3023. https://doi.org/10.1002/joc.3887

Berry, B.J., Okulicz-Kozaryn, A., 2008. Are there ENSO signals in the macroeconomy? Ecological Economics 64, 625-633. https://doi.org/10.1016/j.ecolecon.2007.04.009

Brunner, A.D., 2002. El Niño and World Primary Commodity Prices: Warm Water or Hot Air? Review of Economics and statistics 84, 176-183. https://doi.org/10.1162/003465302317332008

Burgers, G., Stephenson, D.B., 1999. The "normality" of El Niño. Geophysical Research Letters 26, 1027- 1030. https://doi.org/10.1029/1999g1900161

Burke, M., Hsiang, S.M., Miguel, E., 2015. Global non-linear effect of temperature on economic production. Nature 527, 235-239. https://doi.org/10.1038/nature15725 
Cai, W., Santoso, A., Wang, G., Yeh, S.W., An, S.I., Cobb, K.M., Collins, M., Guilyardi, E., Jin, F.F., Kug, J.S., et al., 2015. Enso and greenhouse warming. Nature Climate Change 5, 849.

https://doi.org/10.1038/nclimate2743

Cashin, P., Mohaddes, K., Raissi, M., 2017. Fair weather or foul? The macroeconomic effects of El Niño. Journal of International Economics 106, 37-54. https://doi.org/10.1016/j.jinteco.2017.01.010

Davey, M., Brookshaw, A., Ineson, S., 2014. The probability of the impact of ENSO on precipitation and near-surface temperature. Climate Risk Management 1, 5-24.

https://doi.org/10.1016/j.crm.2013.12.002

Dell, M., Jones, B.F., Olken, B.A., 2014. What Do We Learn from the Weather? The New ClimateEconomy Literature. Journal of Economic Literature 52(3), 740-798. https://doi.org/10.1257/jel.52.3.740

Deschênes, O., Greenstone, M., 2007. The economic impacts of climate change: evidence from agricultural output and random fluctuations in weather. American Economic Review 97, 354-385.

https://doi.org/10.1257/aer.97.1.354

Dilley, M., 1997. Climatic factors affecting annual maize yields in the valley of Oaxaca, Mexico. International Journal of Climatology 17, 1549-1557.

https://doi.org/10.1002/(sici)1097-0088(19971130)17:14<1549::AID-JOC208>3.0.CO;2-N

Driscoll, J., Kraay, A., 1998. Consistent Covariance Matrix Estimation with Spatially Dependent Panel Data. The Review of Economics and Statistics 80(4), 549-560. https://doi.org/10.1162/003465398557825

Fasullo, J., Otto-Bliesner, B., Stevenson, S., 2018. Enso's changing influence on temperature, precipitation, and wildfire in a warming climate. Geophysical Research Letters 45, 9216-9225.

https://doi.org/10.1029/2018gl079022

Hoerling, M.P., Kumar, A., Zhong, M., 1997. El Niño, La Niña, and the Nonlinearity of Their Teleconnections. Journal of Climate 10, 1769-1786.

https://doi.org/10.1175/1520-0442(1997)010<1769:enolna>2.0.co;2

Hsiang, S., Kopp, R.E., 2018. An Economist's Guide to Climate Change Science. Journal of Economic Perspectives 32, 3-32. https://doi.org/10.1257/jep.32.4.3

Hsiang, S.M., Meng, K.C., Cane, M.A., 2011. Civil conflicts are associated with the global climate. Nature 476, 438-441. https://doi.org/10.1038/nature10311

IPCC, 2019. Special Report on the Ocean and Cryosphere in a Changing Climate, Authors: O. Prtner, D.C. Roberts, V. Masson-Delmotte, P. Zhai, M. Tignor, E. Poloczanska, K. Mintenbeck, M. Nicolai, A. Okem, J. Petzold, B. Rama, N. Weyer (eds.). Intergovernmental Panel on Climate Change, Geneva (Switzerland). In press. 
Jin, F.F., An, S.I., Timmermann, A., Zhao, J., 2003a. El Niño and La Niña sea surface temperature anomalies: Asymmetry characteristics associated with their wind stress anomalie. Journal of Geophysical Research 107(D19), ACL 1-10. https://doi.org/10.1029/2001jd000393

Jin, F.F., An, S.I., Timmermann, A., Zhao, J., 2003b. Strong El Niño events and nonlinear dynamical heating. Geophysical Research Letters 30(3), 201-4. https://doi.org/10.1029/2002gl016356

Kahn, M.E., Mohaddes, K., Ng, R.N., Pesaran, M.H., Raissi, M., Yang, J.C., 2019. Long-Term Macroeco- nomic Effects of Climate Change: A Cross-Country Analysis. NBER Working Paper 26167, Cambridge, M.A.: The National Bureau of Economic Research. https://doi.org/10.3386/w26167

Kmenta, J., 1986. Elements of econometrics. 2nd ed. New York: Macmillan.

Kottek, M., Grieser, J., Beck, C., Rudolf, B., Rubel, F., 2006. World Map of the KöGeiger climate classification updated. Meteorologische Zeitschrift 15(3), 259-263.

https://doi.org/10.1127/0941-2948/2006/0130

Kumar, A., Hoerling, M.P., 2003. The nature and causes for the delayed atmospheric response to el niño. Journal of Climate 16, 1391-1403. https://doi.org/10.1175/1520-0442-16.9.1391

Letta, M., Tol, R.S., 2018. Weather, climate and Total Factor Productivity. Environmental and Resource Economics, 1-23.

Lyon, B., 2004. The strength of El Niño and the spatial extent of tropical drought. Geophysical Research Letters 31. https://doi.org/10.1029/2004g1020901

Mason, S.J., Goddard, L., 2001. Probabilistic Precipitation Anomalies Associated with ENSO. Bulletin of the American Meteorological Society 82, 619-638.

https://doi.org/10.1175/1520-0477(2001)082<0619:PPAAWE>2.3.co;2

McKee, T.B., Doesken, N.J., Kleist, J., et al., 1993. The relationship of drought frequency and duration to time scales, in: Proceedings of the 8th Conference on Applied Climatology, American Meteorological Society Boston, MA, 179-183.

Naylor, R.L., Falcon, W.P., Rochberg, D., Wada, N., 2001. Using El Nino/Southern Oscillation Climate Data to Predict Rice Production in Indonesia. Climatic Change 50, 255-265. https://doi.org/10.1023/A:1010662115348

Parker, G., 2013. Global crisis: war, climate change and catastrophe in the seventeenth century. Yale University Press.

Parks, R., 1967. Efficient Estimation of a System of Regression Equations when Disturbances are Both Serially and Contemporaneously Correlated. Journal of the American Statistical Association 62, 500-5097. https://doi.org/10.1080/01621459.1967.10482923 
Penalba, O.C., Rivera, J.A., 2016. Precipitation response to El Niño/La Niña events in Southern South America - emphasis in regional drought occurrences. Advances in Geosciences 42, 1-14.

https://doi.org/10.5194/adgeo-42-1-2016

Pesaran, M.H., 2004. General Diagnostic Tests for Cross Section Dependence in Panels. CESifo working paper 1229, Center for Economic Studies and Ifo Institute (CESifo), Munich.

Pesaran, M.H., 2007. A simple panel unit root test in the presence of cross-section dependence. Journal of applied econometrics 22, 265-312. https://doi.org/10.1002/jae.951

Poveda, G., Mesa, O.J., 1997. Feedbacks between Hydrological Processes in Tropical South America and Large-Scale Ocean-Atmospheric Phenomena. Journal of Climate 10, 2690-2702. https://doi.org/10.1175/1520-0442(1997)010<2690:FBHPIT>2.0.CO;2

Power, S.B., Delage, F.P., 2018. El Niño-Southern Oscillation and Associated Climatic Conditions around the World during the Latter Half of the Twenty-First Century. Journal of Climate 31, 6189-6207. https://doi.org/10.1175/jcli-d-18-0138.1

Sarachik, E.S., Cane, M.A., 2010. The El Niño-Southern Oscillation phenomenon. Cambridge University Press. https://doi.org/10.1017/cbo9780511817496

Smith, S.C., Ubilava, D., 2017. The El Niño Southern Oscillation and economic growth in the developing world. Global Environmental Change 45, 151-164. https://doi.org/10.1016/j.gloenvcha.2017.05.007

Tol, R.S., 2009. The economic effects of climate change. Journal of economic perspectives 23, 29-51. https://doi.org/10.1257/jep.23.2.29

Trenberth, K.E., 1997. The Definition of El Niño. Bulletin of the American Meteorological Society 78, 2771-2778. https://doi.org/10.1175/1520-0477(1997)078<2771:TDOENO>2.0.CO;2

Vicente-Serrano, S.M., Beguería, S., López-Moreno, J.I., Angulo, M., El Kenawy, A., 2010. A New Global 0.5 Gridded Dataset (1901-2006) of a Multiscalar Drought Index: Comparison with Current Drought Index Datasets Based on the Palmer Drought Severity Index. Journal of Hydrometeorology 11(4), 1033-1043. https://doi.org/10.1175/2010jhm1224.1

Vicente-Serrano, S.M., López-Moreno, J.I., Gimeno, L., Nieto, R., Morán-Tejeda, E., LorenzoLacruz, J., Beguería, S., Azorin-Molina, C., 2011. A multiscalar global evaluation of the impact of ENSO on droughts. Journal of Geophysical Research 116, 1-23. https://doi.org/10.1029/2011jd016039

Zhang, Z., Chao, B.F., Chen, J., Wilson, C.R., 2015. Terrestrial water storage anomalies of Yangtze River Basin droughts observed by GRACE and connections with ENSO. Global and Planetary Change 126, 35-45. https://doi.org/10.1016/j.gloplacha.2015.01.002 


\section{Appendix}

Appendix A: Data and statistical information

Table A.1: ENSO country assignment

\begin{tabular}{|c|c|c|c|c|c|c|}
\hline \multirow{2}{*}{ Country } & \multirow{2}{*}{ ISO3 } & \multirow{2}{*}{ Region } & \multirow{2}{*}{ Climate } & \multicolumn{3}{|c|}{$\%$ of croplands } \\
\hline & & & & Trop. & Arid & Temp. \\
\hline Albania & ALB & Europe \& Central Asia & Arid \& Temperate & 0.00 & 0.00 & 1.00 \\
\hline Argentina & ARG & Latin America \& Caribbean & Arid \& Temperate & 0.00 & 0.02 & 0.98 \\
\hline Armenia & $\mathrm{ARM}$ & Europe \& Central Asia & Arid \& Temperate & 0.00 & 0.33 & 0.67 \\
\hline Australia & AUS & East Asia \& Pacific & Arid \& Temperate & 0.00 & 0.57 & 0.43 \\
\hline Burundi & BDI & Sub-Saharan Africa & Tropical \& Humid & 0.80 & 0.00 & 0.20 \\
\hline Benin & BEN & Sub-Saharan Africa & Tropical \& Humid & 0.75 & 0.25 & 0.00 \\
\hline Burkina Faso & BFA & Sub-Saharan Africa & Arid \& Temperate & 0.25 & 0.75 & 0.00 \\
\hline Bangladesh & BGD & South Asia & Tropical \& Humid & 0.87 & 0.00 & 0.13 \\
\hline Bulgaria & BGR & Europe \& Central Asia & Tropical \& Humid & 0.00 & 0.00 & 1.00 \\
\hline Belarus & BLR & Europe \& Central Asia & Arid \& Temperate & 0.00 & 0.00 & 1.00 \\
\hline Belize & BLZ & Latin America \& Caribbean & Tropical \& Humid & 1.00 & 0.00 & 0.00 \\
\hline Bolivia & BOL & Latin America \& Caribbean & Tropical \& Humid & 0.82 & 0.12 & 0.05 \\
\hline Brazil & BRA & Latin America \& Caribbean & Tropical \& Humid & 0.75 & 0.10 & 0.16 \\
\hline Botswana & BWA & Sub-Saharan Africa & Arid \& Temperate & 0.00 & 1.00 & 0.00 \\
\hline Chile & CHL & Latin America \& Caribbean & Arid \& Temperate & 0.00 & 0.01 & 0.99 \\
\hline China & $\mathrm{CHN}$ & East Asia \& Pacific & Arid \& Temperate & 0.00 & 0.32 & 0.68 \\
\hline Cameroon & CMR & Sub-Saharan Africa & Tropical \& Humid & 0.67 & 0.33 & 0.00 \\
\hline Congo, Democratic Republic & COD & Sub-Saharan Africa & Tropical \& Humid & 0.95 & 0.00 & 0.05 \\
\hline Congo & $\mathrm{COG}$ & Sub-Saharan Africa & Tropical \& Humid & 1.00 & 0.00 & 0.00 \\
\hline Colombia & COL & Latin America \& Caribbean & Tropical \& Humid & 0.85 & 0.00 & 0.15 \\
\hline Costa Rica & CRI & Latin America \& Caribbean & Tropical \& Humid & 0.99 & 0.00 & 0.01 \\
\hline Cyprus & CYP & Europe \& Central Asia & Arid \& Temperate & 0.00 & 0.52 & 0.48 \\
\hline Dominican Republic & DOM & Latin America \& Caribbean & Tropical \& Humid & 0.97 & 0.00 & 0.03 \\
\hline Algeria & DZA & Middle East \& North Africa & Arid \& Temperate & 0.00 & 0.31 & 0.69 \\
\hline Ecuador & $\mathrm{ECU}$ & Latin America \& Caribbean & Tropical \& Humid & 0.73 & 0.07 & 0.20 \\
\hline Egypt & EGY & Middle East \& North Africa & Arid \& Temperate & 0.00 & 1.00 & 0.00 \\
\hline Gabon & GAB & Sub-Saharan Africa & Tropical \& Humid & 1.00 & 0.00 & 0.00 \\
\hline Gambia & GMB & Sub-Saharan Africa & Arid \& Temperate & 0.10 & 0.90 & 0.00 \\
\hline Greece & GRC & Europe \& Central Asia & Arid \& Temperate & 0.00 & 0.11 & 0.89 \\
\hline Guatemala & GTM & Latin America \& Caribbean & Tropical \& Humid & 0.85 & 0.00 & 0.15 \\
\hline Honduras & HND & Latin America \& Caribbean & Tropical \& Humid & 0.90 & 0.00 & 0.10 \\
\hline Indonesia & IDN & East Asia \& Pacific & Tropical \& Humid & 1.00 & 0.00 & 0.00 \\
\hline India & IND & South Asia & Tropical \& Humid & 0.36 & 0.36 & 0.28 \\
\hline Iran & IRN & Middle East \& North Africa & Arid \& Temperate & 0.00 & 0.61 & 0.39 \\
\hline Kenya & KEN & Sub-Saharan Africa & Tropical \& Humid & 0.57 & 0.20 & 0.23 \\
\hline Cambodia & KHM & East Asia \& Pacific & Tropical \& Humid & 1.00 & 0.00 & 0.00 \\
\hline Lao People's Democratic Republic & $\mathrm{LAO}$ & East Asia \& Pacific & Tropical \& Humid & 0.87 & 0.00 & 0.13 \\
\hline Sri Lanka & LKA & South Asia & Tropical \& Humid & 1.00 & 0.00 & 0.00 \\
\hline Lesotho & LSO & Sub-Saharan Africa & Arid \& Temperate & 0.00 & 0.00 & 1.00 \\
\hline Morocco & MAR & Middle East \& North Africa & Arid \& Temperate & 0.00 & 0.33 & 0.67 \\
\hline Moldova, Republic of & MDA & Europe \& Central Asia & Arid \& Temperate & 0.00 & 0.00 & 1.00 \\
\hline Madagascar & MDG & Sub-Saharan Africa & Tropical \& Humid & 0.82 & 0.00 & 0.18 \\
\hline Mexico & MEX & Latin America \& Caribbean & Tropical \& Humid & 0.70 & 0.10 & 0.20 \\
\hline Mali & MLI & Sub-Saharan Africa & Arid \& Temperate & 0.20 & 0.80 & 0.00 \\
\hline Mozambique & $\mathrm{MOZ}$ & Sub-Saharan Africa & Arid \& Temperate & 0.33 & 0.57 & 0.10 \\
\hline Mauritania & MRT & Sub-Saharan Africa & Arid \& Temperate & 0.00 & 1.00 & 0.00 \\
\hline
\end{tabular}




\begin{tabular}{|c|c|c|c|c|c|c|}
\hline Mauritius & MUS & Sub-Saharan Africa & Tropical \& Humid & 1.00 & 0.00 & 0.00 \\
\hline Malaysia & MYS & East Asia \& Pacific & Tropical \& Humid & 1.00 & 0.00 & 0.00 \\
\hline Namibia & NAM & Sub-Saharan Africa & Arid \& Temperate & 0.00 & 1.00 & 0.00 \\
\hline Nigeria & NGA & Sub-Saharan Africa & Tropical \& Humid & 0.72 & 0.28 & 0.00 \\
\hline New Zealand & NZL & East Asia \& Pacific & Arid \& Temperate & 0.00 & 0.00 & 1.00 \\
\hline Pakistan & PAK & South Asia & Arid \& Temperate & 0.00 & 0.83 & 0.17 \\
\hline Peru & PER & Latin America \& Caribbean & Tropical \& Humid & 0.48 & 0.24 & 0.28 \\
\hline Philippines & PHL & East Asia \& Pacific & Tropical \& Humid & 0.99 & 0.00 & 0.01 \\
\hline Paraguay & PRY & Latin America \& Caribbean & Arid \& Temperate & 0.34 & 0.07 & 0.59 \\
\hline Romania & $\mathrm{ROU}$ & Europe \& Central Asia & Arid \& Temperate & 0.00 & 0.00 & 1.00 \\
\hline Russian Federation & RUS & Europe \& Central Asia & Arid \& Temperate & 0.00 & 0.19 & 0.81 \\
\hline Sudan & SDN & Sub-Saharan Africa & Arid \& Temperate & 0.07 & 0.93 & 0.00 \\
\hline Senegal & SEN & Sub-Saharan Africa & Arid \& Temperate & 0.02 & 0.98 & 0.00 \\
\hline Sierra Leone & SLE & Sub-Saharan Africa & Tropical \& Humid & 1.00 & 0.00 & 0.00 \\
\hline El Salvador & SLV & Latin America \& Caribbean & Tropical \& Humid & 1.00 & 0.00 & 0.00 \\
\hline Serbia & SRB & Europe \& Central Asia & Arid \& Temperate & 0.00 & 0.00 & 1.00 \\
\hline Swaziland & SWZ & Sub-Saharan Africa & Tropical \& Humid & 1.00 & 0.00 & 0.00 \\
\hline Togo & TGO & Sub-Saharan Africa & Tropical \& Humid & 1.00 & 0.00 & 0.00 \\
\hline Thailand & THA & East Asia \& Pacific & Tropical \& Humid & 1.00 & 0.00 & 0.00 \\
\hline Tajikistan & TJK & Europe \& Central Asia & Arid \& Temperate & 0.00 & 0.68 & 0.32 \\
\hline Tunisia & TUN & Middle East \& North Africa & Arid \& Temperate & 0.00 & 0.04 & 0.96 \\
\hline Turkey & TUR & Middle East \& North Africa & Arid \& Temperate & 0.00 & 0.09 & 0.91 \\
\hline Tanzania & TZA & Sub-Saharan Africa & Tropical \& Humid & 0.72 & 0.20 & 0.08 \\
\hline Uganda & UGA & Sub-Saharan Africa & Tropical \& Humid & 0.94 & 0.04 & 0.02 \\
\hline Ukraine & UKR & Europe \& Central Asia & Arid \& Temperate & 0.00 & 0.00 & 1.00 \\
\hline Uruguay & URY & Latin America \& Caribbean & Arid \& Temperate & 0.00 & 0.00 & 1.00 \\
\hline Venezuela, Bolivarian Republic of & VEN & Latin America \& Caribbean & Tropical \& Humid & 1.00 & 0.00 & 0.00 \\
\hline Vietnam & VNM & East Asia \& Pacific & Tropical \& Humid & 0.67 & 0.00 & 0.33 \\
\hline South Africa & $\mathrm{ZAF}$ & Sub-Saharan Africa & Arid \& Temperate & 0.02 & 0.58 & 0.40 \\
\hline
\end{tabular}


Table A.2: Correlation coefficients between ONI, the Niño 3.4 index and SOI

\begin{tabular}{lccc}
\hline & ONI & SOI & Niño 3.4 index \\
\hline ONI & 1.000 & & \\
SOI & -0.924 & 1.000 & \\
Niño 3.4 index & 0.981 & -0.882 & 1.000 \\
\hline
\end{tabular}

Note: The Niño 3.4 index uses the same region as ONI, but is based on a 5-month running mean. The Equatorial Southern Oscillation Index (SOI) is a standardized index based on the observed sea level pressure differences between eastern equatorial Pacific and Indonesia.

Figure A.2: Evolution of the main ENSO indices (1975-2014)

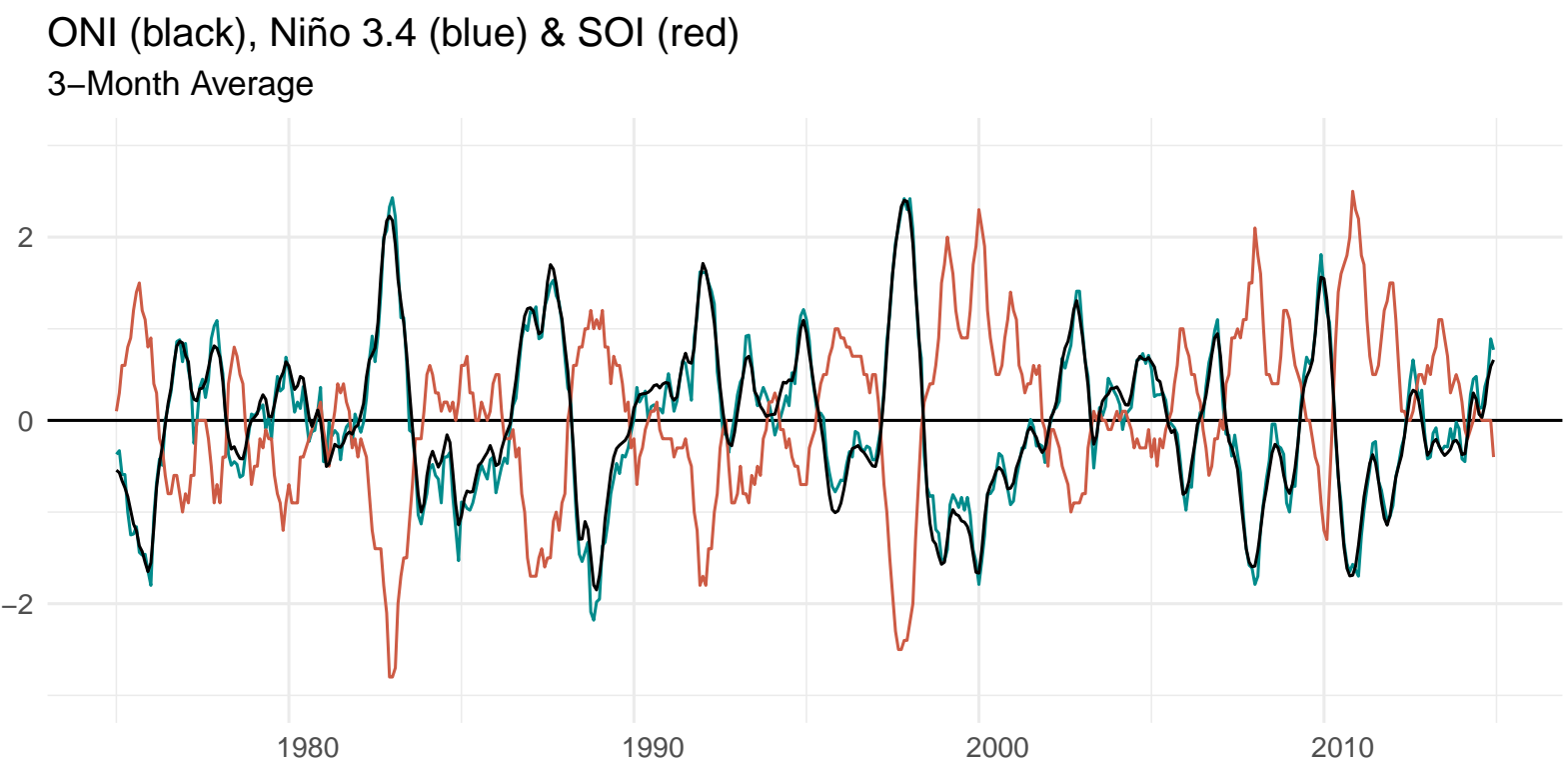

Table A.3: Variables and data sources

\begin{tabular}{lll}
\hline Mnemonic & Source & Variable description \\
\hline ONI & NOAA database & Oceanic Niño Index \\
SPEI & Global SPEI database & Standardised Precipitation-Evapotranspiration Index \\
$y$ & Penn World Table database & Real GDP per capita (in 2011 US dollars) \\
TFP & Penn World Table database & Real Total Factor Productivity per capita \\
& & (Index 2011=1, Annual) \\
\hline
\end{tabular}


Appendix B: Computation of weather series

\section{B.1: The SPEI}

The Standardized Precipitation and Evapotranspiration Index (SPEI) developed by Vicente-Serrano et al. (2010) is calculated, for a month $i$, as the difference $\left(D_{i}\right)$ between precipitation $\left(P_{i}\right)$ and potential evapotranspiration estimates based on the FAO-56 Penman-Monteith equation of water balance $\left(P E T_{i}\right):{ }^{25}$

$$
D_{i}=P_{i}-P E T_{i}
$$

The $D_{i}$ series then reflect the water surplus or deficit for the current month. The calculated $D_{i}$ values are then aggregated at various time scales $k$ (3,6 and 12 months). The aggregated water surplus or deficits values $\left(D_{n}^{k}\right)$ are obtained by the sum of the $D_{i}$ values from $k-1$ months before the $n^{\text {th }}$ current month:

$$
D_{n}^{k}=\sum_{l=0}^{k-1}\left(P_{n-l}-P E T_{n-l}\right) \text { with } n \geq k
$$

Given the strong differences in climatic regimes within and between countries, the $D_{n}^{k}$ series are fitted to a probability distribution to transform the original values to standardized units that are comparable in space and time and at different time scales. A density function of log-logistic probability is adjusted to the distribution of the variable $D_{n}^{k}$ since it allows a better behavior of the SPEI to extreme events. The probability density function of a three parameter Log-logistic distributed variable is expressed as:

$$
f(x)=\frac{\omega}{\theta}\left(\frac{x-\mu}{\vartheta}\right)^{\omega-1}\left(1+\left(\frac{x-\mu}{\vartheta}\right)^{\omega}\right)^{-2}
$$

where $\theta, \omega$ and $\mu$ are parameters of scale, shape and origin for $D_{n}^{k}$ values in the range $(\mu>D<\infty)$. The parameters are estimated using the L-moments procedure. $f(x)$ is transformed into a random variable with mean zero and a variance equals to one. Thus, the value of the SPEI is bounded between -3 and 3 . Between these two values, different intensities in hydro-climatic conditions can be identified, according threshold values reached by the SPEI, as shown in Table B.1.

\footnotetext{
${ }^{25}$ Standardized indicators such as the SPEI are sensitive to the method of calculation of the potential evapotranspiration $(P E T)$. We use a PET estimate based on the Penman-Monteith equation of water balance rather than the Thornthwaite method since Penman-type approach is considered to be more physically realistic.
} 
Table B.1: Hydro-climatic conditions according to threshold values of the SPEI

\begin{tabular}{cl}
\hline Values of SPEI & Hydro-climatic conditions \\
\hline \multicolumn{1}{c}{$S P E I>2$} & Exceptionally moist \\
$1.60<S P E I<1.99$ & Extremely moist \\
$1.30<S P E I<1.59$ & Very moist \\
$0.80<S P E I<1.29$ & Moderately moist \\
$0.51<S P E I<0.79$ & Slightly moist \\
$-0.50<S P E I<0.50$ & Near normal conditions \\
$-0.79<S P E I<-0.51$ & Slightly dry \\
$-1.29<S P E I<-0.80$ & Moderately dry \\
$-1.59<S P E I<-1.30$ & Very dry \\
$-1.99<S P E I<-1.60$ & Extremely dry \\
SPEI $<-2$ & Exceptionally dry \\
\hline Source: NOAA's National Centers for Environmental Infor- \\
mation, 2015.
\end{tabular}

B.2: Deriving the average SPEI by country

Annual SPEI values are obtained by averaging the twelve monthly SPEI of each year included in the period 1975-2014. However, as these values are calculated for every single grid cell, they must be aggregated to the country level to fit the purpose of our paper. We then calculate country-level indicators by taking the average of SPEI across grid cells that overlap a country's cropland areas. In this way, we are able to average weather observations over land covers which are relevant for agriculture and share broadly the same climate, for each country. The cropland areas are defined according to the Global Land Cover SHARE (GLC-SHARE) classification. ${ }^{26}$ We illustrate the advantages of this averaging method by taking the example of Mali in 2010. As can be seen in Figure B.1, Mali is a typical example of a country largely dominated by drylands where little economic activity and sparse populations dominate. Aggregating climate data at the country level without excluding these areas could bias the measurement of climate effects on economic growth and thus fail to accurately identify ENSO impacts channeled through weather conditions prevailing in cropland areas.

\footnotetext{
${ }^{26}$ This Global Land Cover database, developed by the Land and Water Division of Food and Agriculture Organisation (FAO), has a spatial resolution of 30 arc-seconds. This database compiles previously scattered and unharmonized land cover information from around the globe into one centralized database. Eleven land covers types are then aggregated following the Land Cover Classification System (LCCS): artificial surfaces (01), cropland (02), grassland (03), tree covered areas (04), shrubs covered areas (05), herbaceous vegetation, aquatic or regularly flooded (06), mangroves (07), sparse vegetation (08), bare soil (09), snow and glaciers (10), and water bodies (11).
} 
Figure B.1: Land covers distribution, Mali (2010)

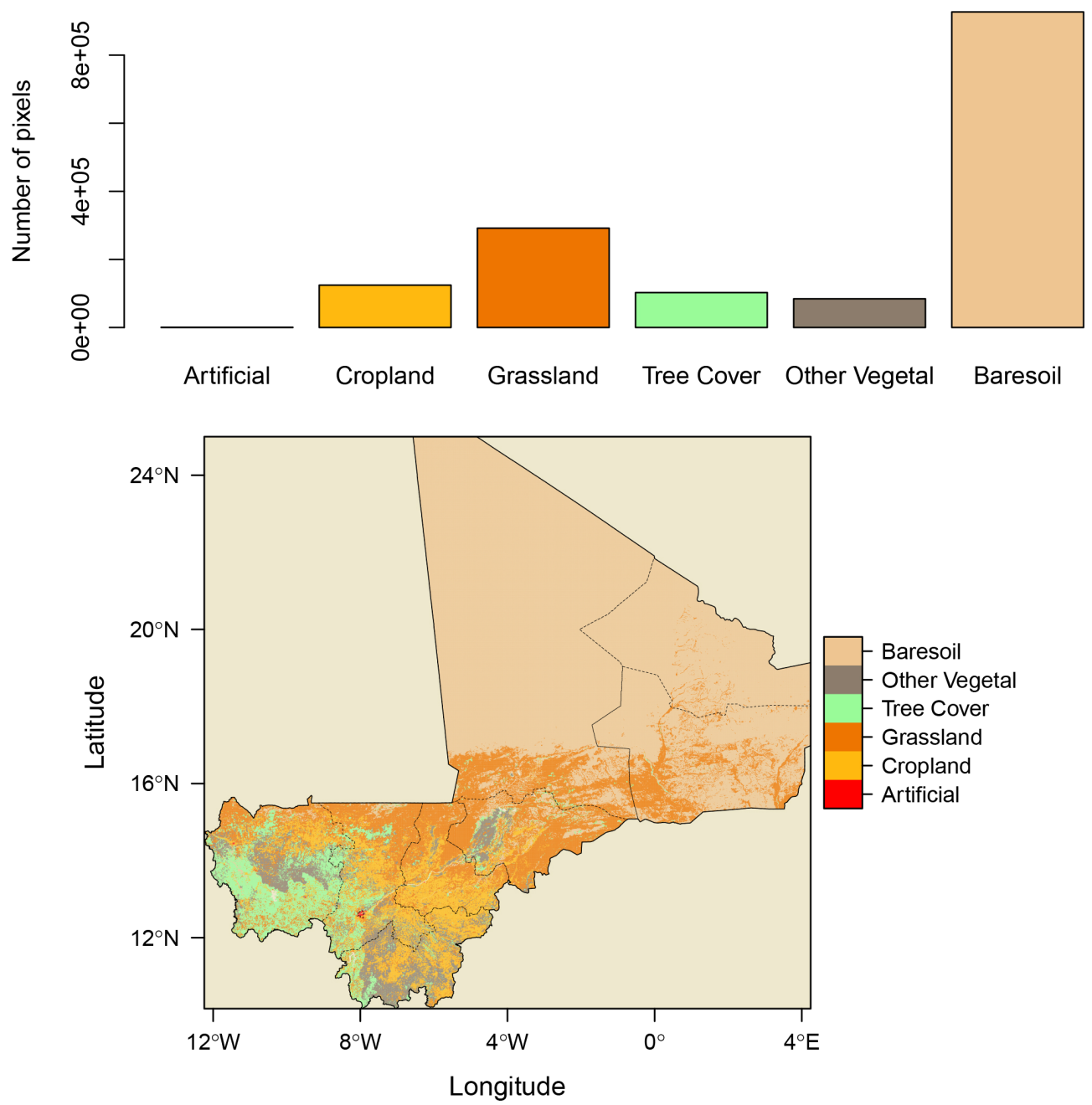

Note: Land covers types are those defined by the GLC-SHARE. For the sake of readability, the category Other Vegetal regroups the following LCCS: shrubs covered areas (05), herbaceous vegetation, aquatic or regularly flooded (06), mangroves (07) and sparse vegetation (08).

Indeed, as shown in Figure B.2, the shape of the SPEI distribution in Mali in 2010 differed considerably depending on the type of land cover. Although $18.2 \%$ of the territory was affected by drier conditions during 2010, the desert areas located in the north of the country were the most challenged by drought. On the contrary, the rest of the country - and particularly croplands - was characterized by wetter conditions. This high spatial variability is therefore likely to smooth out the impact of extreme meteorological conditions during the spatial aggregation process. By contrast, averaging SPEI across grid cells that overlap only cropland areas leads to a value of the SPEI more consistent with weather-related risks in agriculture. 
Figure B.2: SPEI distribution and land cover types, Mali (2010)
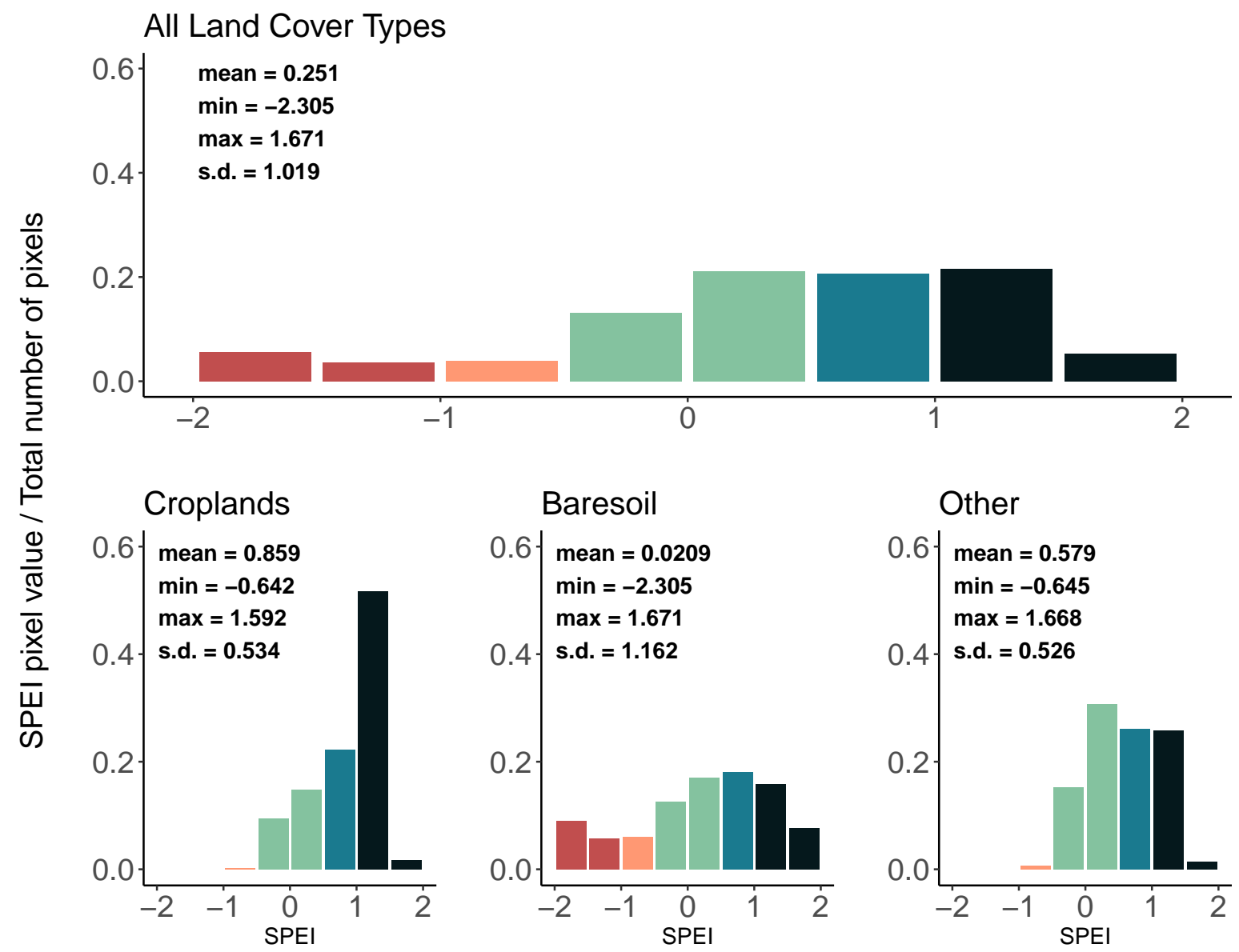
Appendix C: Data analysis

Table C.1: Test for residual

\begin{tabular}{|c|c|c|c|c|}
\hline & \multicolumn{2}{|c|}{ Tropical \& humid countries } & \multicolumn{2}{|c|}{ Arid \& temperate countries } \\
\hline & $\mathrm{FE}$ & $\mathrm{RE}$ & $\mathrm{FE}$ & $\mathrm{RE}$ \\
\hline \multirow[t]{3}{*}{$\mathrm{ONI}_{t} \geq 0$} & $-0.0228^{* * *}$ & $-0.0228^{* * *}$ & $-0.0204^{* * *}$ & $-0.0204^{* * *}$ \\
\hline & $(0.0042)$ & $(0.0042)$ & $(0.0059)$ & $(0.0059)$ \\
\hline & {$[0.0044]$} & {$[0.0043]$} & {$[0.0067]$} & {$[0.0067]$} \\
\hline \multirow[t]{3}{*}{$\mathrm{ONI}_{t}<0$} & $-0.0080^{* *}$ & $-0.0081^{* *}$ & 0.0007 & 0.0006 \\
\hline & $(0.0040)$ & $(0.0040)$ & $(0.0055)$ & $(0.0055)$ \\
\hline & {$[0.0034]$} & {$[0.0034]$} & {$[0.0040]$} & {$[0.0040]$} \\
\hline \multirow{3}{*}{$\mathrm{SPEI}_{t}$} & -0.0040 & -0.0040 & $0.0168^{* * *}$ & $0.0152^{* * *}$ \\
\hline & $(0.0040)$ & $(0.0040)$ & $(0.0056)$ & $(0.0055)$ \\
\hline & {$[0.0038]$} & {$[0.0038]$} & {$[0.0044]$} & {$[0.0040]$} \\
\hline \multirow[t]{3}{*}{$\mathrm{ONI}_{t-1} \geq 0$} & $-0.0148^{* * *}$ & $-0.0148^{* * *}$ & $-0.0150^{* *}$ & $-0.0148^{* *}$ \\
\hline & $(0.0042)$ & $(0.0042)$ & $(0.0059)$ & $(0.0059)$ \\
\hline & {$[0.0047]$} & {$[0.0047]$} & {$[0.0056]$} & {$[0.0056]$} \\
\hline \multirow[t]{3}{*}{$\mathrm{ONI}_{t-1}<0$} & $-0.0073^{*}$ & $-0.0073^{*}$ & -0.0068 & -0.0065 \\
\hline & $(0.0039)$ & $(0.0039)$ & $(0.0054)$ & $(0.0054)$ \\
\hline & {$[0.0050]$} & {$[0.0050]$} & {$[0.0050]$} & {$[0.0051]$} \\
\hline \multirow[t]{3}{*}{$\mathrm{ONI}_{t-1} \geq 0 \times S P E I_{t}$} & $0.0173^{* *}$ & $0.0172^{* *}$ & 0.0092 & 0.0099 \\
\hline & $(0.0077)$ & $(0.0077)$ & $(0.0105)$ & $(0.0105)$ \\
\hline & {$[0.0091]$} & {$[0.0092]$} & {$[0.0093]$} & {$[0.0098]$} \\
\hline \multirow[t]{3}{*}{$\mathrm{ONI}_{t-1}<0 \times S P E I_{t}$} & 0.0126 & 0.0129 & $-0.0226^{* *}$ & $-0.0207^{* *}$ \\
\hline & $(0.0079)$ & $(0.0079)$ & $(0.0098)$ & $(0.0097)$ \\
\hline & {$[0.0061]$} & {$[0.0059]$} & {$[0.0071]$} & {$[0.0068]$} \\
\hline \multirow[t]{3}{*}{ Constant } & $0.0291^{* * *}$ & $0.0291^{* * *}$ & $0.0271^{* * *}$ & $0.0262^{* * *}$ \\
\hline & $(0.0027)$ & $(0.0036)$ & $(0.0036)$ & $(0.0042)$ \\
\hline & {$[0.0029]$} & {$[0.0034]$} & {$[0.0031]$} & {$[0.0040]$} \\
\hline Pesaran CSD & \multicolumn{2}{|c|}{$13.881^{* * *}$} & \multicolumn{2}{|c|}{$11.433^{* * *}$} \\
\hline Autocorrelation Test & \multicolumn{2}{|c|}{$31.809^{* * *}$} & \multicolumn{2}{|c|}{$9.384^{* * *}$} \\
\hline Modified Wald Test & \multicolumn{2}{|c|}{$1650.50^{* * *}$} & \multicolumn{2}{|c|}{$4657.73^{* * *}$} \\
\hline Sargan-Hansen Stat. & \multicolumn{2}{|c|}{$41.245^{* * *}$} & \multicolumn{2}{|c|}{$11.652^{* *}$} \\
\hline Observations & \multicolumn{2}{|c|}{1521} & \multicolumn{2}{|c|}{1299} \\
\hline Countries & \multicolumn{2}{|c|}{39} & \multicolumn{2}{|c|}{36} \\
\hline$R^{2}$ & \multicolumn{2}{|c|}{0.0330} & \multicolumn{2}{|c|}{0.0462} \\
\hline
\end{tabular}

Note: FE stands for fixed effect model and RE for random effect model. Standard errors are in parentheses and robust standard errors are in brackets. ${ }^{* * *},{ }^{* *}$, and ${ }^{*}$ indicate respectively $1 \%, 5 \%$, and $10 \%$ significance levels. 
Table C.2: Pesaran CD test for cross-section independence

\begin{tabular}{lccc}
\hline Variable & CD-test & Correlation & abs(correlation) \\
\hline$\Delta y$ & $32.52^{* * *}$ & 0.100 & 0.189 \\
$\Delta T F P$ & $18.84^{* * *}$ & 0.074 & 0.176 \\
$S P E I$ & $16.91^{* * *}$ & 0.049 & 0.190 \\
\hline
\end{tabular}

Note: The CD test of Pesaran (2004) is defined under the null hypothesis of no cross-sectional dependence. ${ }^{* * *},{ }^{* *}$, and ${ }^{*}$ indicate 1\%, 5\%, and $10 \%$ significance levels.

Table C.3: Cross-sectionally augmented Im, Pesaran and Shin (IPS) test for unit roots

\begin{tabular}{cccccc}
\hline & & \multicolumn{2}{c}{ Without Trend } & \multicolumn{2}{c}{ With Trend } \\
& & \multicolumn{2}{c}{$\bar{Z}_{t}$} \\
\hline Variable & lags & Level & 1st Diff & Level & 1 st Diff \\
\hline$y$ & 0 & $-1.303^{*}$ & $-22.172^{* * *}$ & 1.582 & $-20.611^{* * *}$ \\
& 1 & $-4.597^{* * *}$ & $-16.116^{* * *}$ & $-1.006^{*}$ & $-13.775^{* * *}$ \\
& 2 & $-1.862^{*}$ & $-9.484^{* * *}$ & 0.029 & $-6.503^{* * *}$ \\
& 3 & -0.043 & $-7.642^{* * *}$ & 1.193 & $-4.647^{* * *}$ \\
\hline$T F P$ & 0 & 0.551 & $-25.898^{* * *}$ & -0.616 & $-23.710^{* * *}$ \\
& 1 & -1.117 & $-18.277^{* * *}$ & $-3.622^{* * *}$ & $-15.081^{* * *}$ \\
& 2 & 0.319 & $-11.668^{* * *}$ & -1.342 & $-7.921^{* * *}$ \\
& 3 & 0.596 & $-8.316^{* * *}$ & -0.457 & $-4.695^{* * *}$ \\
\hline SPEI & 0 & $-27.432^{* * *}$ &. & $-25.218^{* * *}$ &. \\
& 1 & $-19.007^{* * *}$ &. & $-16.925^{* * *}$ &. \\
& 2 & $-12.899^{* * *}$ &. & $-10.686^{* * *}$ &. \\
& 3 & $-8.541^{* * *}$ &. & $-6.387^{* * *}$ &. \\
\hline
\end{tabular}

Note: ${ }^{* * *},{ }^{* *}$, and $^{*}$ denote the rejection of the null hypothesis at the $10 \%, 5 \%$ and $1 \%$ level. The null hypothesis is the presence of unit root in panel data with cross-sectional dependence in the form of common factor dependence. 
Table C.4: Results from System-GMM estimates, Heaviside variable

\begin{tabular}{|c|c|c|c|c|c|c|}
\hline & \multicolumn{3}{|c|}{ Tropical \& humid countries } & \multicolumn{3}{|c|}{ Arid \& temperate countries } \\
\hline & (1) & $(2)$ & (3) & $(4)$ & $(5)$ & $(6)$ \\
\hline$\Delta y_{t-1}$ & $\begin{array}{c}0.366^{* * *} \\
(0.0619)\end{array}$ & $\begin{array}{c}0.361^{* * *} \\
(0.0619)\end{array}$ & $\begin{array}{c}0.355^{* * *} \\
(0.0606)\end{array}$ & $\begin{array}{c}0.336^{* * *} \\
(0.0745)\end{array}$ & $\begin{array}{l}0.343^{* * *} \\
(0.0705)\end{array}$ & $\begin{array}{r}0.353^{* * *} \\
(0.0695)\end{array}$ \\
\hline $\mathrm{ONI}_{t} \geq 0$ & $\begin{array}{c}-0.0094^{* *} \\
(0.0045)\end{array}$ & $\begin{array}{l}-0.0085^{*} \\
(0.0046)\end{array}$ & $\begin{array}{c}-0.0099^{* *} \\
(0.0043)\end{array}$ & $\begin{array}{c}-0.0164^{* *} \\
(0.0065)\end{array}$ & $\begin{array}{c}-0.0136^{* *} \\
(0.0063)\end{array}$ & $\begin{array}{c}-0.0146^{* *} \\
(0.0058)\end{array}$ \\
\hline $\mathrm{ONI}_{t}<0$ & $\begin{array}{l}-0.0014 \\
(0.0033)\end{array}$ & $\begin{array}{l}-0.0018 \\
(0.0033)\end{array}$ & $\begin{array}{l}-0.0022 \\
(0.0029)\end{array}$ & $\begin{array}{c}0.0000 \\
(0.0042)\end{array}$ & $\begin{array}{c}0.0020 \\
(0.0044)\end{array}$ & $\begin{array}{c}0.0002 \\
(0.0039)\end{array}$ \\
\hline $\mathrm{SPEI}_{t}$ & & $\begin{array}{c}0.0042^{* *} \\
(0.0020)\end{array}$ & $\begin{array}{l}-0.0035 \\
(0.0028)\end{array}$ & & $\begin{array}{c}0.0135^{* * *} \\
(0.0040)\end{array}$ & $\begin{array}{c}0.0227^{* * *} \\
(0.0064)\end{array}$ \\
\hline $\mathrm{ONI}_{t-1} \geq 0$ & & & $\begin{array}{l}-0.0036 \\
(0.0050)\end{array}$ & & & $\begin{array}{l}-0.0064 \\
(0.0051)\end{array}$ \\
\hline $\mathrm{ONI}_{t-1}<0$ & & & $\begin{array}{l}-0.0059 \\
(0.0050)\end{array}$ & & & $\begin{array}{c}-0.0129^{* * *} \\
(0.0045)\end{array}$ \\
\hline $\mathrm{ONI}_{t-1} \geq 0 \times S P E I_{t}$ & & & $\begin{array}{c}0.0206^{* *} \\
(0.0089)\end{array}$ & & & $\begin{array}{l}-0.0064 \\
(0.0095)\end{array}$ \\
\hline $\mathrm{ONI}_{t-1}<0 \times S P E I_{t}$ & & & $\begin{array}{l}0.0080 * \\
(0.0047)\end{array}$ & & & $\begin{array}{c}-0.0347^{* * *} \\
(0.0102)\end{array}$ \\
\hline Constant & $\begin{array}{c}0.0128^{* * *} \\
(0.0019) \\
\end{array}$ & $\begin{array}{c}0.0128^{* * *} \\
(0.0020)\end{array}$ & $\begin{array}{c}0.0156^{* * *} \\
(0.0037) \\
\end{array}$ & $\begin{array}{c}0.0148^{* * *} \\
(0.0030)\end{array}$ & $\begin{array}{c}0.0146^{* * *} \\
(0.0031) \\
\end{array}$ & $\begin{array}{c}0.0190^{* * *} \\
(0.0035) \\
\end{array}$ \\
\hline $\begin{array}{l}\text { Observations }(N \times T) \\
\chi^{2}\end{array}$ & $\begin{array}{c}1482 \\
75.61^{* * *}\end{array}$ & $\begin{array}{c}1482 \\
83.47^{* * *}\end{array}$ & $\begin{array}{c}1482 \\
108.2^{* * *}\end{array}$ & $\begin{array}{c}1263 \\
36.20^{* * *}\end{array}$ & $\begin{array}{c}1263 \\
71.32^{* * *}\end{array}$ & $\begin{array}{c}1263 \\
157.3^{* * *}\end{array}$ \\
\hline \multicolumn{7}{|c|}{ Tests of over-identification restrictions } \\
\hline $\begin{array}{l}\text { Sargan test: } \chi^{2}(36) \\
\text { Hansen test: } \chi^{2}(36)\end{array}$ & $\begin{array}{c}86.70^{* * *} \\
35.15\end{array}$ & $\begin{array}{c}85.28^{* * *} \\
34.90\end{array}$ & $\begin{array}{c}87.77^{* * *} \\
33.32\end{array}$ & $\begin{array}{c}109.4^{* * *} \\
33.95\end{array}$ & $\begin{array}{c}109.9^{* * *} \\
35.01\end{array}$ & $\begin{array}{c}106.4^{* * *} \\
30.84\end{array}$ \\
\hline \multicolumn{7}{|c|}{ Arellano-Bond test for $\mathrm{AR}(1)$ in first differences } \\
\hline $\begin{array}{l}z \\
\operatorname{Pr}>z\end{array}$ & $\begin{array}{c}-4.624 \\
0.000\end{array}$ & $\begin{array}{c}-4.621 \\
0.000\end{array}$ & $\begin{array}{c}-4.600 \\
0.000\end{array}$ & $\begin{array}{c}-3.901 \\
0.000\end{array}$ & $\begin{array}{c}-3.956 \\
0.000\end{array}$ & $\begin{array}{c}-3.961 \\
0.000\end{array}$ \\
\hline \multicolumn{7}{|c|}{ Arellano-Bond test for $\operatorname{AR}(2)$ in first differences } \\
\hline$z$ & -0.469 & -0.396 & -0.370 & 0.622 & 0.586 & 0.459 \\
\hline $\operatorname{Pr}>z$ & 0.639 & 0.692 & 0.712 & 0.534 & 0.558 & 0.646 \\
\hline
\end{tabular}

Note: ${ }^{* * *},{ }^{* *}$, and $^{*}$ denote the rejection of the null hypothesis at the $10 \%, 5 \%$ and $1 \%$ level. Robust standard errors are in parentheses. We restrict the maximum lag length of the lagged instruments to one lag. Results are insensitive to the choice of alternative maximum lag lengths. Results using up to four lags are available upon request. 